\title{
A Probabilistic Fatigue Approach for Riveted Joints Using
}

\section{Monte Carlo Simulation}

\author{
Rui F. Sanches ${ }^{\mathrm{a}}$, Abílio M.P. de Jesus ${ }^{\mathrm{b}, \mathrm{c}, 1}$, José A.F.O. Correia ${ }^{\mathrm{b}, \mathrm{c}}$, A.L.L. da Silva ${ }^{\text {b,c }}$, A.A. \\ Fernandes ${ }^{\mathrm{b}, \mathrm{c}}$ \\ ${ }^{a}$ University of Trás-os-Montes e Alto Douro, School of Sciences and Technology, Engineering \\ Department, 5000-801 Vila Real, Portugal
}

${ }^{\mathrm{b}}$ Faculty of Engineering, University of Porto, Rua Dr. Roberto Frias, 4200-465 Porto, Portugal

${ }^{\mathrm{c} I N E G I, ~ R u a ~ D r . ~ R o b e r t o ~ F r i a s, ~ 4200-465 ~ P o r t o, ~ P o r t u g a l ~}$

\begin{abstract}
The availability of probabilistic fatigue strength $\mathrm{S}-\mathrm{N}$ data for riveted connections is essential to carry out reliability analysis of ancient riveted bridges. This paper proposes a procedure to derive probabilistic $\mathrm{S}-\mathrm{N}$ fields for riveted connections, using material fatigue data and detailed finite element modelling of the joints. Strain-life fatigue data of the plain material as well as fatigue crack growth data are used to compute the total fatigue life of a riveted connection, integrating both the local and fracture mechanics approaches to fatigue. The basic fatigue data is inputted in the probabilistic form as well as some relevant parameters of the model which are subjected to higher uncertainty. Three dimensional finite element modelling of the riveted joint is carried out to assess
\end{abstract}

${ }^{1}$ Corresponding author: e-mail: ajesus@fe.up.pt; Phone: +351 22508 1740; Fax: +351 22508 1445; mail address: Mechanical Engineering Department, SMPT, Faculty of Engineering, University of Porto, Rua Dr. Roberto Frias, 4200-465 Porto, Portugal. 
the local stresses/strains at the critical location, as well as the stress intensity factor history, for an expected growing fatigue crack. The proposed approach allows the assessment of the effects of both clamping stresses on rivets and friction coefficient, on local stress/strain values and stress intensity factors. The clamping stresses on rivets and friction coefficient are assumed random variables. The inputs, in the probabilistic form, are accounted in the fatigue strength assessment procedure using the Monte Carlo sampling technique. Resulting $p-S-N_{f}$ field computed for a simple riveted joint is compared with experimental data, illustrating a very satisfactory performance of the model. In addition, the sensibility of the $p-S-N_{f}$ field to some input parameters is discussed.

KEYWORDS: Riveted Joints; Puddle Iron; Fatigue Crack Initiation; Fatigue Crack Propagation; Probabilistic Approach; Monte Carlo Simulation.

\section{INTRODUCTION}

All across the world there are a very significant number of old riveted highway and railway bridges in operation, which may show important fatigue damage levels. The long operational period of these structures, typically characterized by increasing traffic intensity, both in terms of vehicle gross weights/axle loads as well as truck/train crossing frequencies, contributes to the reduction of the current structural reliability of these structures, mainly due to fatigue damaging progress. Many of the old riveted bridges were not originally designed taking into account the fatigue process, since fatigue design procedures only appeared in design codes some decades after their construction. This issue raises concerns about the likely poor original bridge fatigue detailing. 
A number of fatigue assessment methodologies for riveted railway bridges have been proposed in the past [1][2], some being of probabilistic form [3][4][5]. The proposed probabilistic approaches seek the probability of failure or the reliability index, being inherent the comparison of the probabilistic fatigue strength data with the probabilistic fatigue loading. Some of the proposed methodologies for fatigue assessment of riveted bridges aimed the estimation of the remaining fatigue life of the primary members of the bridge (main girders, stringers, cross-girders) [1][2][3][4][5] and are supported by simplified global models of the bridge. However, most of the fatigue-damage related cases that have been reported for the riveted bridges were observed on riveted connections between the primary members and the fatigue damage has been attributed to secondary effects (e.g. out of plane deformation) [6][7]. Very few fatigue assessments of riveted connections have been based on detailed stress analysis such as that provided by finite element models [8][9][10].

Current design codes of practice propose the use of global S-N approaches to assess the fatigue resistance of riveted joints. In many cases, a unique S-N curve is proposed independently of the joint geometric configuration, which may be inappropriate for all kind of riveted joints [11]. Also, code based S-N curves are usually presented in deterministic form which difficult their application for reliability analysis. Design code S-N curves are developed based on a statistical analysis of a significant database of fatigue tests performed on riveted details covering distinct steels and riveted joint configurations. All the data is correlated together and statistical analysis (e.g. linear regression analysis) is used to specify the mean $\mathrm{S}-\mathrm{N}$ curve and convenient safety margins. This is the case of AREMA, BS5400 and EC3 procedures. These code approaches are global ones incorporating significant safety margins in order to be applicable to the diversity of riveted joint geometries and materials. 
Local approaches to fatigue allow the effects of the actual geometry and material properties to be properly accounted in the fatigue behaviour of the joint [12]. Also, for the particular case of the riveted joints, the use of local approaches allows the clamping stress on rivets and friction effects to be conveniently accounted [13].

This paper presents a procedure to generate probabilistic stress-life data for riveted shear splices, integrating both the local strain and Fracture Mechanics based fatigue approaches. Strain-life and fatigue crack propagation data from the plain material are provided in the probabilistic form. A detailed 3D finite element (FE) model of the riveted joint is proposed to assess the elastoplastic strains at the critical locations as well as the stress intensity factor histories for a feasible propagating crack. These outputs of the FE model are expressed as a function of the clamping stresses on rivets and friction coefficient. Both clamping stresses and friction coefficient are assumed random inputs of the proposed procedure to estimate the probabilistic S-N field, following assumed probability density functions. The elastoplastic strains are required for computation of crack initiation within the framework of the local strain approaches to fatigue. The stress intensity factors are used to compute the crack propagation until failure. The initial defect assumed in the crack propagation process is also assumed a random variable of the procedure.

The probabilistic stress-life field is derived for a riveted joint using the Monte Carlo simulation method. The inputs of a base deterministic model are previously converted into statistical distributions. The output of the model - the total fatigue life - is evaluated from random inputs, selected respecting their statistical distributions. This process is carried out over a high number of simulations to result the probability density 
distribution of the total number of cycles to failure. This process is demonstrated for a simple riveted connection made of puddle iron from the Fão road bridge.

The procedure presented in this paper can be actually used as an alternative to the global approaches foreseen in design codes. It is more time consuming since it requires fatigue properties of base materials and accurate finite element models of the joint. However it allows a clear understanding of the influent parameters on fatigue behaviour as well as to specify appropriate safety margins from a probabilistic model framework.

\section{PROPOSED PROBABILISTIC MODELLING APPROACH}

In this paper, a model for the fatigue behaviour prediction of riveted joints is proposed, based on the assumption that fatigue damage is regarded as a process of macroscopic crack initiation followed by a process of macroscopic crack propagation. Therefore, the total fatigue life may be evaluated according to the following relation:

$$
N_{f}=N_{i}+N_{p}
$$

where $N_{f}$ is the total number of cycles to failure, $N_{i}$ is the number of cycles to initiate a macroscopic crack and $N_{p}$ is the number of cycles to propagate the crack until failure. To compute the number of cycles to initiate the crack, the local approaches to fatigue, based on the strain-life data from smooth specimens is used. For this purpose and since a probabilistic model is aimed, the probabilistic strain-life field, as originally proposed by Castillo and Fernández-Canteli, based on the Weibull distribution, is adopted to compute the crack initiation [14][12]: 


$$
N_{i}=\exp \left[B+\frac{\lambda+\delta(-\log (1-p))^{1 / \beta}}{\log \left(\varepsilon_{a}\right)-C}\right]
$$

where $p$ is probability of failure, $\varepsilon_{a}$ is the strain amplitude, $\lambda, \delta$ and $\beta$ are Weibull constants and $B$ and $C$ are additional model parameters. Parameters $B$ and $C$ may be estimated using a constrained least squares method; parameters $\lambda, \beta$ and $\delta$ may be computed using the maximum likelihood method [14].

Concerning the simulation of the fatigue crack propagation, the Linear Elastic Fracture Mechanics based Paris law is adopted [15]:

$$
\frac{d a}{d N}=C \Delta K^{m}
$$

where $C$ and $m$ are material constants, $\Delta K$ is the stress intensity factor range and $d a / d N$ is the fatigue crack propagation rate. The number of cycles to propagate the crack, $N_{p}$, results from the integration of the Paris law, between an initial defect, $a_{i}$, and a final defect $a_{f}$ :

$$
N_{p}=\frac{1}{C} \int_{a_{i}}^{a_{f}} \frac{1}{\Delta K^{m}} d a
$$

The previous integral may be solved numerically, using the following incremental form for the number of cycles:

$$
N_{p}=\sum_{i=1}^{n_{\text {inc }}} \Delta N_{i} ; \quad \Delta N_{i}=\frac{\Delta a_{i}}{C \Delta K_{i}^{m}}
$$

The crack is propagated according predefined crack increments, assuming constant the stress intensity factor, during each increment. This approximation yields very satisfactory results if the crack increments are kept small.

Several sources of uncertainty may arise when computing the number of cycles to propagate a crack. One source of uncertainty is introduced by the estimation of the parameters of the propagation law. Additionally, the crack initiation criterion may play 
an important influence on the final result of the integral of Eq. (5). In the literature, the local approaches to fatigue have been used to model a macroscopic crack initiation, but distinct definitions have been adopted. Several initial crack size criteria have been

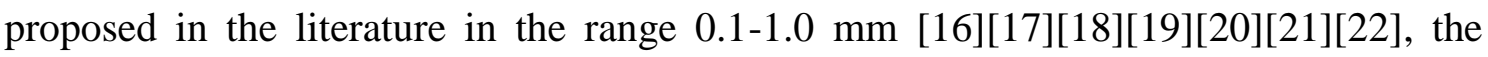
value of $0.5 \mathrm{~mm}$ being a very common definition. In the proposed procedure, the macroscopic crack initiation size is assumed a source of uncertainty of the model itself and therefore $a_{i}$ is assumed a random variable, following a proposed probabilistic distribution. The critical crack size, $a_{f}$, is estimated based on the material toughness which was assumed a deterministic property. Any possible variability in the material toughness will show a very low influence in the fatigue crack propagation life prediction results, since the crack propagation rates for cracks approaching the critical size are very high, resulting in a negligible variation in the total number of cycles to failure.

Two additional sources of uncertainty were accounted in the prediction procedure: the clamping stresses on rivets and the friction coefficient. These two parameters show very high uncertainty in the riveted joints; consequently they were accounted as random variables in the fatigue modelling process. These parameters were assumed inputs of the finite element models proposed for the riveted joint under investigation and have an influence on relations between the applied stress range and the local strain histories, as well as the stress intensity factor histories.

Figure 1 illustrates the procedure proposed to compute the fatigue life, $N_{f}$, for riveted connections, given the applied net stress range, $\Delta \sigma_{\text {net }}$. The inputs of the model that are defined in probabilistic form (random variables) are pointed out in the figure, namely: the clamping stresses on rivets, the friction coefficient, the crack initiation size, $a_{i}$, and the $C$ coefficient of the Paris law. In addition, the strain-life model is also proposed in 
the probabilistic form. The number of cycles to crack initiation is assumed a random variable for a given strain amplitude.

The procedure depicted in Figure 1 requires the support of a finite element model to compute the stress intensity factor histories and the local elastoplastic strains due to the combined clamping and friction coefficient effects. Concerning the stress intensity factors computation, the Virtual Crack Closure Technique was adopted which requires the computation of the nodal displacement and nodal forces at the crack vicinity [23]. Regarding the elastoplastic analysis, it can be performed using an elastoplastic finite element analysis or an elastic finite element analysis followed by a post-processing simplified elastoplastic analysis. The elastoplastic finite element analysis can be performed using a cycle-by-cycle analysis which requires multiple load step analyses to extract the local strain range. Alternatively, the twice yield method (TWM), as proposed by Kalnins [26], may be used to extract the local elastoplastic strain range. The latter method is numerically efficient since it requires only one load step analysis. Concerning the post-processing simplified elastoplastic analysis, several possibilities may be used, the Neuber [24] or Seeger-Heuler [25] proposals being two possibilities.

The proposed procedure consists on a probabilistic modelling that is based on a statistical simulation of a deterministic model. Some important deterministic variables are replaced by random variables. Each of these random variables is described by a statistical distribution, which is based on experimental data and/or empirical assumptions. Furthermore, the probabilistic modelling uses a probabilistic model to correlate the strain-life data. The output of the model - the probability density function of the number of cycles to failure, is computed using a sampling technique, the Monte Carlo method being selected. A value for each probabilistic input is randomly selected from its statistical distribution and calculations of the number of cycles to failure are performed. The random inputs are defined using the cumulative probability 
distributions. Random numbers are generated in the range 0-1 and are entered in the ordinates of the cumulative probability distributions, the respective abscissa being the random input. This process is also used in the definition of the number of cycles to initiate the crack, using the equation (2). After definition of the strain amplitude, a probability of failure, $p$, is randomly selected between 0 and $100 \%$ resulting the corresponding random number of cycles to initiate the crack.

This process is repeated preferably for a significant number of times. The number of cycles to failure is tabulated and the respective probability density distribution generated.

\section{EXPERIMENTAL DATA}

This section presents the experimental fatigue data required to illustrate the proposed procedure for the derivation of probabilistic fatigue strength data for riveted connections. Firstly, the riveted connection is described and the respective experimental fatigue strength data is presented. Then, the plain material fatigue data is presented and the respective statistical distributions are selected.

Riveted joints made of puddle iron were prepared according to the specifications of Figure 2. The riveted joints consisted of double shear connections. Rivets with $22 \mathrm{~mm}$ of diameter were applied into holes of $24 \mathrm{~mm}$ of diameter.

The material required to prepare the riveted joints was extracted from side diagonals replaced in the Fão bridge. The Fão bridge is a riveted metallic road bridge that crosses the Cávado river at Esposende in the northwest region of Portugal. This bridge was inaugurated on $7^{\text {th }}$ August 1892. This bridge has a total length of 267 meters, composed of 8 spans of 33.5 meters each, supported on 7 masonry piers. The material used to 
build the bridge was puddle iron. In the last rehabilitation of the bridge, some side diagonals were replaced. Those diagonals were used to manufacture a series of riveted joints that were tested under fatigue loading.

Tensile tests of smooth round specimens revealed a yield stress of $220 \pm 37 \mathrm{MPa}$, a tensile strength of $359 \pm 29 \mathrm{MPa}$ and a strain at failure of $23 \pm 7 \%$ [27].

A total of 15 riveted joints were fatigue tested under stress control with a stress R-ratio equal to 0 . Figure 3 represents the $\mathrm{S}-\mathrm{N}$ fatigue data. The ordinate represents the average stress range evaluated in the middle plates, at the cross section containing the axis of the rivets and is perpendicular to the loading. The average $\mathrm{S}-\mathrm{N}$ curve is also proposed. A determination coefficient, $\mathrm{R}^{2}=0.83$ was found, which represents a satisfactory correlation, taking into account that puddle irons show a significant level of inclusions and other kind of heterogeneities.

Fatigue tests of smooth specimens of puddle iron were carried out under strain control, according to the ASTM E606 standard [28]. Two series of specimens were tested, namely with strain ratios equal to -1 (14 specimens) and equal to 0 (20 specimens). Figure 4 represents the experimental data points. The Weibull probabilistic strain-life model by Castillo and Fernández-Canteli [14] was used to correlate the strain-life fatigue data. The following set of parameters was obtained for the puddle iron from the Fão bridge: $B=-0.2268, C=-8.4017, \lambda=12.4363, \beta=5.5814, \delta=8.4153$. Figure 4 presents the percentile curves for probabilities of failures, $p$, of $1 \%, 5 \%, 50 \%, 95 \%$ and $99 \%$. The figure also represents the deterministic Morrow's equation [29] for comparison purposes with the probabilistic strain-life field. This curve is almost coincident with the $50 \%$ percentile curve for high cycle fatigue; for low-cycle fatigue, some deviation is verified between the two curves. Figure 5 represents cumulative probability 
distributions of the number of reversals to failure, for several values of strain amplitude, $\varepsilon_{a}$

Note that both Figure 4 and Figure 5 refer to the number of cycles to failure, $N_{f}$, of the small-scale smooth specimens. This data will be used in this paper to model the crack initiation, $N_{i}$ for the riveted joint.

The strain-controlled fatigue tests were also applied to derive cyclic elastoplastic constants of the puddle iron. In particular, the cyclic coefficient and exponent of the Ramberg-Osgood equation [30] were derived taking into account the conjunction of the two tested series, resulting: $K^{\prime}=713 \mathrm{MPa}$ and $n^{\prime}=0.119$. These parameters were assumed deterministic in this analysis. These parameters were important since they defined the cyclic curve which was used as input of the elastoplastic finite element model.

Crack propagation data was also derived for the puddle iron using compact tension (CT) specimens, according to the ASTM E647 standard [31]. Crack propagation data was obtained for stress R-Ratio, $\mathrm{R}=0$. A total of 4 specimens were tested, and respective results are illustrated in Figure 6. Figure 6 shows the evolution of the crack growth rate $(\mathrm{da} / \mathrm{dN})$ as a function of the stress intensity factor range $(\Delta K)$. The experimental data was correlated using the Paris law [15], resulting a determination coefficient or the linear regression analysis, $\mathrm{R}^{2}=0.791$. The $C$ and $m$ parameters are included in Figure 6 and are average values, taking into account the results from the four tested specimens.

In order to account for the variability of the fatigue crack growth rates, the parameters of the Paris law may be assumed as random variables. However, $C$ and $m$ parameters should not be assumed simultaneously as random independent variables, since it would over predict the fatigue crack growth rates. Very often, the $m$ exponent is correlated with the $C$ coefficient, but to derive this correlation, significant amount of tests is required, which is not the case of this study. 
One possibility considered in this study to account for the scatter in the fatigue crack propagation rates was to assume $C$ parameter to follow a LogNormal distribution with exponent $m$ fixed and equal to the experimental average value $(m=4.8038)$. A mean value for the $C$ constant equal to $4.2047 \mathrm{E}-18$ was assumed with a coefficient of variation $(\mathrm{CoV})$ equal to $50 \%$ (reference simulation, refer to Table 1). Another possibility considered in this study consisted of a fixed $C$ parameter equal to 4.2047E-18 and $m$ exponent following a LogNormal distribution with an average value equal to 4.8038 and $\mathrm{CoV}$ equal to $1.5 \%$ (simulation 12 , refer to Table 1 ).

Figure 7 illustrates the cumulative probability distribution of the $C$ coefficient for the case it was assumed a random variable. Using the two proposed alternative distributions for the parameters of the Paris law, two sets of 254 random values of da/dN vs. $\Delta \mathrm{K}$ lines were generated and plotted in Figure 8 (black lines). The superposition of the experimental data shows similar scatter than the predicted da/dN curves. The graphs of Figure 8 also include bounding da/dN vs $\Delta \mathrm{K}$ lines that resulted from 1000 simulations.

\section{FINITE ELEMENT ANALYSIS OF THE RIVETED JOINT}

A 3D FE model of the riveted connection was built to compute the local elastoplastic strains as well as the stress intensity factor histories for a propagating fatigue crack, taking into account the combined effects of friction and clamping stresses on rivets. The FE model was built using the ANSYS ${ }^{\circledR}$ commercial code [32] using 20-noded isoparametric solid elements. The contact between plates and rivets were modelled using contact finite elements that are governed by the Augmented Lagrange contact algorithm. Surface-to-surface contact technology and flexible-to-flexible surface behaviour was used. ANSYS® default contact parameters were adopted in the analysis 
[32]. However, a stiffness penalty factor, FKN, equal to 0.1 was adopted and a penetration tolerance factor, FTOLN, equal to 0.1 was used.

Figure 9 shows the finite element mesh of the riveted connection. Only 1/8 of the geometry was modelled taking advantage of the existing planes of symmetry (see Figure 2).

Rivets may apply a clamping effect on riveted joints due to the plastic deformation and cooling process inherent to the riveting process. This clamping effect was simulated in the FE model assuming a non-null thermal expansion coefficient for the rivet along its axial direction. A first load step, consisting on a temperature variation applied to the rivet, was applied prior to the tensile loading in order to result the clamping stresses. The temperature variation was calibrated to achieve precise clamping stresses. The exact value of the clamping stresses developing in rivets from riveted connections is an unknown, which may be handled in a probabilistic point of view. It must be emphasized that clamping stresses on rivets are not significant as in preloaded high strength bolts. More details about the finite element model can be found in reference [13].

A number of distinct clamping stresses were simulated between null clamping stress and $200 \mathrm{MPa}$. The response of the riveted joint for other clamping stresses than simulated may be obtained by interpolation. In the same way as the clamping stresses on rivets, the friction coefficient may be assumed a random variable. For the purpose of the finite element simulations, three distinct friction coefficients were simulated, namely $\mu=0.15$, $\mu=0.35$ and $\mu=0.60$. Results for other friction coefficients were obtained via interpolation/extrapolation.

Figure 10 shows the evolution of the stress intensity factor with the clamping stress and friction coefficient for several crack sizes starting with a size of $0.175 \mathrm{~mm}$. Linear elastic simulations were performed using crack size increments of $0.175 \mathrm{~mm}$. A thru- 
thickness constant depth symmetrical crack was modelled at the central plate, starting at the stress concentration, at the surface of the hole of the rivet, and propagating perpendicularly to the loading. The stress intensity factor was evaluated for several crack lengths (a), using the virtual crack closure technique (VCCT) [23]. Nodal forces and displacements at the crack tip vicinity were adopted for this computation. Although the VCCT allows the evaluation of the stress intensity factor thru the thickness, average thru-thickness values were computed and plotted in Figure 10. These average stress intensity factors were normalized using the average (nominal) stress at the net section of the central plate.

Besides the linear elastic simulations that were proposed to compute the stress intensity factors, non-linear elastoplastic analyses were also performed in order to relate the local elastoplastic strain ranges with the applied net stress range, resulting the so-called component cyclic curve. The elastoplastic analysis was performed using the $\mathrm{J} 2$ plasticity model (von Mises yield criterion) available in ANSYS [32] and adopting a multilinear kinematic hardening, based on Besseling model [33]. The plasticity model was identified using stabilized cyclic data of the material (see Section 3).

Two possibilities for the elastoplastic finite element analysis were pondered. The first one consisted on a cycle-by-cycle elastoplastic analysis. This approach consists on simulating the loading history, for a number of complete loading cycles and covering distinct stress amplitudes, requiring the analysis of several load steps. The analysis of the computed elastoplastic strain history allows the assessment of the local strain ranges. Each simulation of the loading history will result in a point of the component cyclic stress-strain curve. Alternatively, the Twice Yield Technique may be used to simulate the component cyclic elastoplastic curves of the component in an efficient way. This technique, originally proposed by Kalnins [26], only requires the simulation of one load step to obtain the complete component cyclic stress-strain curve. In this 
case, the component is simulated imposing a stress range and the strain results are understood as strain amplitudes. Instead of the cyclic curve of the material, the twice yield cyclic curve of the material is needed to define the material stress-strain relation. Figure 11 compares the component cyclic curves obtained using the Cycle-by-Cycle and Twice Yield Method. These curves were simulated for a null nominal stress ratio and for a friction coefficient of 0.15 and null clamping stresses on rivets. The two techniques produced almost coincident results until a net stress range of approximately $500 \mathrm{MPa}$. The cycle-by-cycle technique was not able to simulate net strain ranges above this value since that domain is not realistic for the components under $\mathrm{R}=0$. The Twice Yield Method is not sensitive to the stress ratio, therefore it was applied for a wider net stress range domain that could happen for negative stress ratios.

Figure 11 also includes two additional component cyclic curves that were simulated using analytical elastoplastic analysis, in particular the Neuber [24] and Seeger-Heuler [25] analyses. These analytical models require the elastic stress distribution which was also computed using the un-cracked finite element model. These two models gave very similar results until the net stress range of about $500 \mathrm{MPa}$; above this value a divergence was observed between the models. Clearly, the Neuber approach is not adequate for very high net strain ranges, since this approach is not valid for generalized plastic conditions. The Seeger-Heuler model produced more consistent component cyclic curves for very high net stress ranges since this model was a generalization of the Neuber approach for generalized plastic conditions. Taking into account the results presented in Figure 11, it was decided to adopt the Twice Yield Method to compute the component cyclic curves for several combinations of friction coefficients and clamping stresses.

Figure 12 presents the component cyclic elastoplastic curves generated for the riveted joint. These curves give the relation between the applied net stress range and the 
resulting local/peak plastic strain range. These curves were obtained using an elastoplastic finite element analysis of the riveted joint (Twice Yield Method), taking into account distinct clamping stresses and friction coefficients. The local elastoplastic strains for other conditions than simulated may be computed through interpolation/extrapolation of results presented in Figure 12.

\section{PROBABILISTIC SIMULATION}

\subsection{Input Probabilistic Distributions}

Probabilistic fatigue simulations were performed using the Monte Carlo sampling technique, aiming the generation of $p-S-N_{f}$ fields for the riveted joint. Table 1 summarizes the combinations of input probabilistic density functions that were considered in a parametric study performed in this research. Simulation 1 is proposed as a reference simulation that resulted in a very satisfactory prediction of the probabilistic $p-S-N_{f}$ field for the rived joint under investigation, using realistic assumptions for the input functions. For this reference simulation, the clamping stress was assumed to follow a LogNormal probability density function with a mean value of $25 \mathrm{MPa}$ and a standard deviation of $10 \mathrm{MPa}$. It was assumed a low average clamping stress on rivets which is a well-known characteristic of this type of joints. Concerning the friction coefficient, a triangular probability density function was postulated with the minimum value of 0.1 and the maximum value of 0.6 , with a most likely value of 0.3 . The most likely value is a value often adopted in the literature in simulation of riveted joints [10]. Both probability density functions of clamping stresses and friction coefficient were estimated based on an empirical basis. Concerning the simulation of the fatigue crack propagation, the Paris law was integrated with a $C$ parameter following a LogNormal distribution with a mean value of 4.20E-18 and a coefficient of variation of $50 \%$. The $m$ 
parameter was assumed fixed for the reference simulation. These assumptions concerning the Paris law parameters were validated by experimental fatigue crack propagation data available for the material, as demonstrated in Section 3.

Taking into account the usual range for the crack initiation size criterion adopted in the literature, a triangular probability density function with a minimum value of $0.1 \mathrm{~mm}$, a maximum value of $1.0 \mathrm{~mm}$ and a most likely value of $0.5 \mathrm{~mm}$ was used to define the macroscopic crack initiation for the reference simulation.

The Twice Yield Method was used in the majority of simulations, including the reference one, to perform the elastoplastic analysis required to estimate the local elastoplastic strains, given the net stress range.

The proposed parametric study aimed the investigation of the effects of the input probability density functions and their parameters on probabilistic S-N fields. With respect to the clamping stresses on rivets, two alternative LogNormal density functions were simulated with higher and lower mean clamping stress values (simulations 2, 3, $11,16)$ than reference simulation. In addition, triangular density functions were also simulated for the clamping stress. The most likely values for these density functions were assumed equal to the mean clamping stress value considered in the reference simulation. The minimum clamping stress was kept null and the maximum values changed between 100MPa (simulation 4) and $200 \mathrm{MPa}$ (simulation 5).

Concerning the friction coefficient, besides the triangular probability density function adopted in the reference simulation, two more triangular functions were tested with the same extreme values than used in the reference simulation, but with distinct most likely values (simulations 6 and 7). Also LogNormal probability density functions were simulated for this parameter, in particular with mean values, $\mu=0.3$ (simulations 8 and 9) and $\mu=0.5$ (simulations $10,11,15$ ). Distinct coefficient of variations were assumed 
for these LogNormal density functions, namely $10 \%$ (simulation 8 ) and $30 \%$ (simulations 9, 10, 11, 15).

The parametric study also investigated the effects of the Paris law parameters definition. While the reference simulation considered the $C$ parameter as a random variable, following the LogNormal density function, with $m$ being a constant, simulation 12 considered the $m$ parameter as a random variable and $C$ a fixed parameter. In this last simulation, $m$ followed a LogNormal distribution with the mean value equal to the average value of the experimental results and a coefficient of variation equal to $1.5 \%$.

For the crack initiation size, two alternative triangular density functions were simulated in addition to the reference simulation. In these alternative density functions, the extreme values were kept the same of the reference simulation, but distinct most likely values were tested.

Finally, the parametric study also considered the possibility of performing the elastoplastic analysis by means of the Neuber approach (simulations 15 and 16). Simulation 15 considered the same conditions of the reference simulation except the elastoplastic analysis that was performed using the Neuber approach. Simulation 16 analyses the effects of the Neuber analysis in a condition of high friction coefficient combined with high clamping stresses on rivets.

Figure 13 illustrates the input distributions used for the reference simulation, which were estimated using 10000 samples.

\subsection{Results and discussion}

Figure 14 illustrates some results of the reference simulation, in the form of probabilistic density functions that resulted from a net stress range of $291 \mathrm{MPa}$, applied to the riveted joint. In particular, probabilistic density functions are presented for the 
elastoplastic strain amplitude as well as for the number of cycles to initiate, propagate a crack and the total number of cycles experienced by the riveted joint. Figure 16, Figure 17 and Figure 18 present the probabilistic S-N fields generated for the riveted joint, which takes into account, respectively, the crack initiation, crack propagation and the total fatigue lives. The analysis of these figures illustrates a very good agreement between the $p-S-N_{f}$ and the experimental data. Also, one can conclude that the crack initiation phase is dominant damaging process. Therefore, the inputs of the probabilistic approach that impacts directly on fatigue crack propagation do not have significant influence on $p-S-N_{f}$ field prediction. The crack initiation size and the scatter in the Paris propagation law fit this category of inputs. Figure 15 presents the component probabilistic cyclic curves field that takes into account the effects of scatter of both clamping stresses and friction coefficient on cyclic curves.

Figure 19 to Figure 21 compare the $p-S-N_{f}$ field produced by the reference simulation with the $p-S-N_{f}$ field resulted from other simulations corresponding to variations in the input density functions, as summarized in Table 1 . In these figures, the $p-S-N_{f}$ fields are represented by the percentile curves corresponding to $1 \%, 50 \%$ and $99 \%$ probability of failure. Figure 19 compares the reference simulation with the simulations 2, 3, 4 and 5. These comparisons highlight the effects of changes in the clamping stress probabilistic density functions. For the LogNormal density function, the increase of the mean clamping stress from 25 to $50 \mathrm{MPa}$ still produces satisfactory $p-S$ - $N_{f}$ fields: the experimental data fits inside the $1 \%-99 \%$ probability band. The increase of the standard deviation from $10(\mathrm{CoV}=40 \%)$ to $20 \mathrm{MPa}(\mathrm{CoV}=80 \%)$ only affected the percentile curves corresponding to higher probability of failures (e.g. $p=99 \%$ ), leading to an improvement of the $p-S-N_{f}$ description since all experimental data now fits the $1 \%-99 \%$ probability band. The consideration of triangular probability density functions for the clamping stress also produced very satisfactory results, but with the minimum, most 
likely and maximum values equal, respectively to 0, 100 and $25 \mathrm{MPa}$. If the maximum value increases till $200 \mathrm{MPa}$, the $1 \%-99 \%$ probability band still includes the experimental data, but the distribution of the experimental data around the $50 \%$ percentile curve gets poorer. Simulations 6 and 7 did not produce noticeable changes in the $p-S-N_{f}$ field with respect to the reference simulation. The change in the most likely value of the friction coefficient between 0.2 and 0.4 did not influence the fatigue life prediction, for clamping stress according to the reference simulation. The change in the probability density function from triangular to LogNormal function did not result in changes in the predicted $p-S-N_{f}$ field, with respect to the reference simulation, provided that the mean value of the friction coefficient is kept equal to 0.3. Therefore, figures corresponding to simulations 6 to 9 are omitted in the paper.

Figure 20 clarifies that for an average friction coefficient equal to 0.5 , a visible change in the $p-s-N_{f}$ fields is observed. Also it is clear that the LogNormal distribution of the friction coefficient with a mean value of 0.5 and $\mathrm{CoV}$ of $10 \%$, combined with the reference clamping stress distribution led to an improved $p-s-N_{f}$ field, when a comparison is performed with the reference simulation. The combination of high friction coefficient (simulation 10) with high clamping stresses (simulation 2) produced an unreliable $p-s-N_{f}$ field (simulation 11).

Simulations 12, 13 and 14 did not produce noticeable changes in the reference $p-s-N_{f}$ field. On effect, since the fatigue crack propagation is not the governing damage phenomenon for the investigated riveted joint, any plausible changes in the Paris law parameters and in the crack initiation criterion do not correspond to changes in the global $p-s-N_{f}$ field. 
Table 1 - Summary of the parametric study.

\begin{tabular}{|c|c|c|c|c|c|}
\hline Simulation & $\begin{array}{c}\text { Clamping Stress } \\
{[\mathrm{MPa}]}\end{array}$ & $\begin{array}{l}\text { Friction } \\
\text { coefficient }\end{array}$ & $\begin{array}{l}\text { Paris Law } \\
\text { Parameters }\end{array}$ & $\begin{array}{l}\text { Crack Initiation } \\
\left.\text { Criterion, } \mathbf{a}_{\mathbf{i}} \mathbf{m m}\right]\end{array}$ & $\begin{array}{c}\text { Elastoplastic } \\
\text { Analysis }\end{array}$ \\
\hline $\begin{array}{c}1 \\
\text { (reference) }\end{array}$ & $\begin{array}{l}\text { LogNormal: } \\
\text { Mean }=25 ; \\
\text { Sdt Dev }=10\end{array}$ & $\begin{array}{c}\text { Triangular: } \\
\text { Min }=0.1 ; \text { Max }=0.6 \\
\text { Most Likely }=0.3\end{array}$ & $\begin{array}{c}C, \text { LogNormal: } \\
\text { Mean }=4.20 \mathrm{E}-18 \\
\text { CoV }=50 \% \\
m, \text { constant }\end{array}$ & $\begin{array}{c}\text { Triangular: } \\
\text { Min }=0.1 ; \mathrm{Max}=1.0 \\
\text { Most Likely }=0.5\end{array}$ & TWM \\
\hline 2 & $\begin{array}{l}\text { LogNormal: } \\
\text { Mean }=50 ; \\
\text { Sdt Dev }=10\end{array}$ & $\begin{array}{c}\text { Triangular: } \\
\text { Min }=0.1 ; \mathrm{Max}=0.6 \\
\text { Most Likely }=0.3\end{array}$ & $\begin{array}{c}C, \text { LogNormal: } \\
\text { Mean }=4.20 \mathrm{E}-18 \\
\text { CoV }=50 \% \\
m, \text { constant }\end{array}$ & $\begin{array}{c}\text { Triangular: } \\
\text { Min=0.1;Max }=1.0 \\
\text { Most Likely }=0.5\end{array}$ & TWM \\
\hline 3 & $\begin{array}{l}\text { LogNormal: } \\
\text { Mean=25; } \\
\text { Std Dev }=20\end{array}$ & $\begin{array}{c}\text { Triangular: } \\
\text { Min }=0.1 ; \mathrm{Max}=0.6 \\
\text { Most Likely }=0.3\end{array}$ & $\begin{array}{c}C, \text { LogNormal: } \\
\text { Mean }=4.20 \mathrm{E}-18 \\
\text { CoV }=50 \% \\
m, \text { constant } \\
\end{array}$ & $\begin{array}{c}\text { Triangular: } \\
\text { Min }=0.1 ; \operatorname{Max}=1.0 \\
\text { Most Likely }=0.5\end{array}$ & TWM \\
\hline 4 & $\begin{array}{c}\text { Triangular: } \\
\text { Min=0; } \text { Max=100; } \\
\text { Most Likely=25 }\end{array}$ & $\begin{array}{c}\text { Triangular: } \\
\text { Min }=0.1 ; \mathrm{Max}=0.6 \\
\text { Most Likely }=0.3\end{array}$ & $\begin{array}{c}C, \text { LogNormal: } \\
\text { Mean }=4.20 \mathrm{E}-18 \\
\text { CoV=50\% } \\
m, \text { constant }\end{array}$ & $\begin{array}{c}\text { Triangular: } \\
\text { Min=0.1;Max }=1.0 \\
\text { Most Likely }=0.5\end{array}$ & TWM \\
\hline 5 & $\begin{array}{c}\text { Triangular: } \\
\text { Min=0; Max=200; } \\
\text { Most Likely=25 }\end{array}$ & $\begin{array}{c}\text { Triangular: } \\
\text { Min }=0.1 ; \text { Max }=0.6 \\
\text { Most Likely }=0.3\end{array}$ & $\begin{array}{c}C, \text { LogNormal: } \\
\text { Mean }=4.20 \mathrm{E}-18 \\
\text { CoV }=50 \% \\
m, \text { constant }\end{array}$ & $\begin{array}{c}\text { Triangular: } \\
\text { Min }=0.1 ; \operatorname{Max}=1.0 \\
\text { Most Likely }=0.5\end{array}$ & TWM \\
\hline 6 & $\begin{array}{l}\text { LogNormal: } \\
\text { Mean }=25 ; \\
\text { Sdt Dev }=10\end{array}$ & $\begin{array}{c}\text { Triangular: } \\
\text { Min }=0.1 ; \mathrm{Max}=0.6 \\
\text { Most Likely }=0.2\end{array}$ & $\begin{array}{c}C, \text { LogNormal: } \\
\text { Mean }=4.20 \mathrm{E}-18 \\
\text { CoV }=50 \% \\
m, \text { constant } \\
\end{array}$ & $\begin{array}{c}\text { Triangular: } \\
\text { Min }=0.1 ; \operatorname{Max}=1.0 \\
\text { Most Likely }=0.5\end{array}$ & TWM \\
\hline 7 & $\begin{array}{l}\text { LogNormal: } \\
\text { Mean }=25 ; \\
\text { Sdt Dev }=10\end{array}$ & $\begin{array}{c}\text { Triangular: } \\
\text { Min }=0.1 ; \operatorname{Max}=0.6 \\
\text { Most Likely }=0.4\end{array}$ & $\begin{array}{c}C, \text { LogNormal: } \\
\text { Mean }=4.20 \mathrm{E}-18 \\
\mathrm{CoV}=50 \% \\
m, \text { constant } \\
\end{array}$ & $\begin{array}{c}\text { Triangular: } \\
\text { Min }=0.1 ; \operatorname{Max}=1.0 \\
\text { Most Likely }=0.5\end{array}$ & TWM \\
\hline 8 & $\begin{array}{l}\text { LogNormal: } \\
\text { Mean }=25 ; \\
\text { Sdt Dev }=10\end{array}$ & $\begin{array}{l}\text { LogNormal: } \\
\text { Mean }=0.3 ; \\
\text { CoV=10\% }\end{array}$ & $\begin{array}{c}C, \text { LogNormal: } \\
\text { Mean }=4.20 \mathrm{E}-18 \\
\text { CoV }=50 \% \\
m, \text { constant }\end{array}$ & $\begin{array}{c}\text { Triangular: } \\
\text { Min=0.1;Max }=1.0 \\
\text { Most Likely }=0.5\end{array}$ & TWM \\
\hline 9 & $\begin{array}{l}\text { LogNormal: } \\
\text { Mean }=25 ; \\
\text { Sdt Dev }=10\end{array}$ & $\begin{array}{l}\text { LogNormal: } \\
\text { Mean }=0.3 ; \\
\operatorname{CoV}=30 \%\end{array}$ & $\begin{array}{c}C, \text { LogNormal: } \\
\text { Mean }=4.20 \mathrm{E}-18 \\
\text { CoV }=50 \% \\
m, \text { constant }\end{array}$ & $\begin{array}{c}\text { Triangular: } \\
\text { Min }=0.1 ; \mathrm{Max}=1.0 \\
\text { Most Likely }=0.5\end{array}$ & TWM \\
\hline 10 & $\begin{array}{l}\text { LogNormal: } \\
\text { Mean }=25 ; \\
\text { Sdt Dev }=10\end{array}$ & $\begin{array}{l}\text { LogNormal: } \\
\text { Mean }=0.5 ; \\
\text { CoV=10\% }\end{array}$ & $\begin{array}{c}C, \text { LogNormal: } \\
\text { Mean }=4.20 \mathrm{E}-18 \\
\text { CoV }=50 \% \\
m, \text { constant }\end{array}$ & $\begin{array}{c}\text { Triangular: } \\
\text { Min }=0.1 ; \text { Max }=1.0 \\
\text { Most Likely }=0.5\end{array}$ & TWM \\
\hline 11 & $\begin{array}{l}\text { LogNormal: } \\
\text { Mean }=50 ; \\
\text { Std Dev }=10\end{array}$ & $\begin{array}{l}\text { LogNormal: } \\
\text { Mean }=0.5 ; \\
\text { CoV }=10 \%\end{array}$ & $\begin{array}{c}C, \text { LogNormal: } \\
\text { Mean }=4.20 \mathrm{E}-18 \\
\text { CoV }=50 \% \\
m, \text { constant }\end{array}$ & $\begin{array}{c}\text { Triangular: } \\
\text { Min=0.1;Max }=1.0 \\
\text { Most Likely }=0.5\end{array}$ & TWM \\
\hline 12 & $\begin{array}{l}\text { LogNormal: } \\
\text { Mean }=25 ; \\
\text { Sdt Dev }=10\end{array}$ & $\begin{array}{c}\text { Triangular: } \\
\text { Min }=0.1 ; \mathrm{Max}=0.6 \\
\text { Most Likely }=0.3\end{array}$ & $\begin{array}{c}m, \text { LogNormal: } \\
\text { Mean }=4.8038 ; \\
\text { CoV }=1.5 \% \\
C, \text { constant }\end{array}$ & $\begin{array}{c}\text { Triangular: } \\
\text { Min }=0.1 ; \mathrm{Max}=1.0 \\
\text { Most Likely }=0.5\end{array}$ & TWM \\
\hline 13 & $\begin{array}{l}\text { LogNormal: } \\
\text { Mean=25; } \\
\text { Sdt Dev }=10\end{array}$ & $\begin{array}{c}\text { Triangular: } \\
\text { Min }=0.1 ; \mathrm{Max}=0.6 \\
\text { Most Likely }=0.3\end{array}$ & $\begin{array}{c}C, \text { LogNormal: } \\
\text { Mean }=4.20 \mathrm{E}-18 \\
\text { CoV }=50 \% \\
m, \text { constant }\end{array}$ & $\begin{array}{c}\text { Triangular: } \\
\text { Min }=0.1 ; \\
\text { Max }=1.0 \\
\text { Most Likely }=0.25\end{array}$ & TWM \\
\hline 14 & $\begin{array}{l}\text { LogNormal: } \\
\text { Mean }=25 ; \\
\text { Sdt Dev }=10\end{array}$ & $\begin{array}{c}\text { Triangular: } \\
\text { Min }=0.1 ; \text { Max }=0.6 \\
\text { Most Likely }=0.3\end{array}$ & $\begin{array}{c}C, \text { LogNormal: } \\
\text { Mean }=4.20 \mathrm{E}-18 \\
\text { CoV }=50 \% \\
m, \text { constant } \\
\end{array}$ & $\begin{array}{c}\text { Triangular: } \\
\text { Min }=0.1 ; \\
\text { Max }=1.0 ; \\
\text { Most Likely }=0.75\end{array}$ & TWM \\
\hline 15 & $\begin{array}{l}\text { LogNormal: } \\
\text { Mean }=25 ; \\
\text { Sdt Dev }=10\end{array}$ & $\begin{array}{c}\text { Triangular: } \\
\text { Min }=0.1 ; \text { Max }=0.6 \\
\text { Most Likely }=0.3\end{array}$ & $\begin{array}{c}C, \text { LogNormal: } \\
\text { Mean }=4.20 \mathrm{E}-18 \\
\text { CoV }=50 \% \\
m, \text { constant } \\
\end{array}$ & $\begin{array}{c}\text { Triangular: } \\
\text { Min }=0.1 ; \text { Max }=1.0 \\
\text { Most Likely }=0.5\end{array}$ & Neuber \\
\hline 16 & $\begin{array}{l}\text { LogNormal: } \\
\text { Mean }=50 ; \\
\text { Std Dev }=10\end{array}$ & $\begin{array}{l}\text { LogNormal: } \\
\text { Mean }=0.5 \\
\text { CoV }=10 \%\end{array}$ & $\begin{array}{c}C, \text { LogNormal: } \\
\text { Mean }=4.20 \mathrm{E}-18 \\
\text { CoV }=50 \% \\
m, \text { constant }\end{array}$ & $\begin{array}{c}\text { Triangular: } \\
\text { Min }=0.1 ; \text { Max }=1.0 \\
\text { Most Likely }=0.5\end{array}$ & Neuber \\
\hline
\end{tabular}


Figure 21 shows the influence of the elastoplastic analysis adopted to compute the local elastoplastic strains of the riveted joint. In particular, the use of the analytical Neuber analysis instead of the FEM based Twice Yield Method analysis, influences the $p-s-N_{f}$ fields, namely for upper percentile curves and for lower fatigue lives. This influence is clearer for the combination of high clamping stresses and high friction coefficients.

A distribution fitting exercise was performed to identify analytical probabilistic density functions that best fit the simulated distributions for the local strain amplitude and for the number of cycles of failure. This exercise was carried out using results from simulation 1. Figure 22 represents the simulated distributions and the analytical distributions that best fitted the simulation results, for an applied net stress range of $355 \mathrm{MPa}$.

Table 2 quantifies the goodness of fit of several tested analytical distributions measured according three statistical tests: Kolmogorov-Smirnov, Anderson-Darling and the $\chi$-Square tests. The Weibull distribution was the one that best fitted the local strain amplitude. The number of cycles to failure followed the Pearson6 distribution followed by the LogNormal distribution. The LogNormal distribution has been proposed often to correlate S-N fatigue data.

To conclude the results analysis and discussion, a comparison between the $p-s-N_{f}$ field obtained with the reference simulation and the $\mathrm{S}-\mathrm{N}$ curves given by design codes, are presented in Figure 23. In particular the AREMA class D S-N curve is plotted. The Taras and Greiner [11] S-N curve proposed for this kind of riveted joints is also plotted. The analysis of the results shows that the slope of the AREMA S-N curve is not adequate leading to very significant life overestimations for high-cycle fatigue and unsafe predictions for the medium/low-cycle fatigue. The Taras and Greiner curve produced a better approximation to the $p-s-N_{f}$ field since these authors proposed 
recently for this type of riveted joints a change of the S-N curve slope to $m=5$ and also an increase in the fatigue strength at $2 \times 10^{6}$ cycles to $90 \mathrm{MPa}$. With this change, the resulting S-N curve seems to be more consistent with the generated $p-s-N_{f}$ field until $3 \times 10^{4}$ cycles. For these fatigue regimes the Taras and Greiner curve becomes significantly more conservative than the proposed $p-s-N_{f}$ field. Taras and Greiner referred the need to use different fatigue categories to distinguish distinct groups of riveted joints. This is a new development regarding the current design codes of practice. The research presented in this paper impulses forward this tendency proposing a methodology to generate S-N curves that takes into account the particularities of each riveted joint (e.g. material, geometry, manufacturing parameters) and the scatter in the parameters governing fatigue behaviour.

Table 2 - Goodness of fit statistical tests, for several probabilistic density functions.

\begin{tabular}{|l|l|l|l|l|l|}
\hline \multicolumn{5}{|c|}{ Local Strain Amplitude } \\
\hline Kolmogorov-Smirnov & \multicolumn{2}{|c|}{ Anderson-Darling } & \multicolumn{2}{c|}{$\chi$-Square } \\
\hline Weibull & 0.0584 & Weibull & 57.12 & Weibull & 682.46 \\
\hline BetaGeneral & 0.0698 & BetaGeneral & 80.59 & BetaGeneral & 812.01 \\
\hline Gauss Inverse & 0.1328 & Gamma & 401.10 & Gamma & 3757.59 \\
\hline Gamma & 0.1372 & Gauss Inverse & 404.76 & Gauss Inverse & 3899.33 \\
\hline LogNormal & 0.1396 & LogNormal & 420.53 & LogNormal & 3923.63 \\
\hline Exponential & 0.5768 & Exponential & 4327.30 & Triangular & 57022.20 \\
\hline Triangular & 0.7475 & Triangular & 12871.42 & Uniform & 117253.77 \\
\hline Uniform & 0.8406 & Uniform & 17912.85 & Exponential & 269605.58 \\
\hline \multicolumn{5}{|c|}{ Number of cycles to failure } & \multicolumn{2}{|c|}{} \\
\hline \multicolumn{2}{|c|}{ Kolmogorov-Square } \\
\hline Pearson6 & 0.0059 & Pearson6 & 0.41 & Pearson6 & 74.89 \\
\hline LogNormal & 0.0141 & LogNormal & 2.99 & LogNormal & 98.78 \\
\hline LogLogistic & 0.0143 & LogLogistic & 5.17 & Gauss Inverse & 143.93 \\
\hline Gauss Inverse & 0.0203 & Gauss Inverse & 7.74 & LogLogistic & 167.90 \\
\hline Pearson5 & 0.0357 & Pearson5 & 27.12 & Pearson5 & 322.35 \\
\hline Gamma & 0.0589 & Exponential & 846.92 & Gamma & 696.63 \\
\hline Weibull & 0.0873 & Triangular & 15897.10 & Weibull & 1665.51 \\
\hline Exponential & 0.2232 & Uniform & 21209.16 & Exponential & 4426.03 \\
\hline Triangular & 0.7913 & Gamma & Infinite & Triangular & 74204.33 \\
\hline Uniform & 0.8692 & Weibull & Infinite & Uniform & 150058.43 \\
\hline
\end{tabular}




\section{CONCLUSIONS}

A procedure to derive probabilistic S-N fields for riveted connections was proposed based on Monte Carlo simulation technique. Both crack initiation and propagation were accounted in the procedure. Several inputs were specified in the probabilistic form such as the material fatigue properties. Also, friction and clamping effects on rivets were assumed in the probabilistic form as well as the crack initiation size definition, to account for the uncertainty associated to these parameters. The procedure was applied to a riveted connection made of puddle iron extracted from an ancient riveted bridge. The predicted probabilistic S-N field was very consistent with the experimental S-N data, demonstrating the good performance of the procedure.

For the investigated rived joint, the fatigue crack initiation was the dominating damage mechanism. Therefore, the input parameters of the model that have direct influence on fatigue crack propagation modelling had a minor influence on the global prediction of the $p-S-N_{f}$ field of the riveted joint. Friction and clamping stresses on rivets may have a strong influence on fatigue crack initiation, since these parameters impacts directly the local strains. Results shown that clamping stresses on rivets should follow a distribution with a relative low average values - between 25 and $50 \mathrm{MPa}$. For an average clamping stress of $25 \mathrm{MPa}$, the average/most likely values of the friction coefficient may vary between 0.2 and 0.5 without influencing appreciably the $p-S-N_{f}$ field.

The elastoplastic analysis performed using the Twice Yield Method was numerically efficient when compared with other approaches such as the cycle-by-cycle analysis.

The results confirmed that for a given applied stress range, the local elastoplastic strain follows a Weibull distribution and the number of cycles follows the Pearson6 distribution. The LogNormal distribution is also a good candidate to describe the 
number of cycles to failure, which is a well-accepted distribution in the literature for this purpose.

The proposed approach may be extended to more complex riveted joints, the number of random parameters increased as needed. Material, production and model uncertainties may be conveniently accounted by the proposed procedure, resulting a probabilistic tool to generate $p-S-N$ fields for riveted joints, which are important for reliability analysis of old riveted bridges.

Existing code-based S-N curves did not show good agreement with the proposed $p-S-N_{f}$ field, resulting in over conservative predictions for high-cycle fatigue. Particularly, the universal slope proposed by code recommendations seems not adequate for any type of riveted joints. The proposed approach allows the derivation of S-N curves suitable for the typology of the riveted joints.

\section{ACKNOWLEDGEMENTS}

The authors acknowledge the Portuguese Science Foundation (FCT) for the financial support given by the PhD grants SFRH/BD/66497/2009 and SFRH/BD/72434/2010.

\section{REFERENCES}

[1] DiBattista, J.D., Adamson, D.E.J., Kulak, G.L, 1998, "Evaluation of remaining fatigue life for riveted truss bridges", Canadian Journal of Civil Engineering 25(4):678-691.

[2] Geissler, K., 2002, “Assessment of old steel bridges, Germany”, Structural Engineering International $12(4): 258-263$

[3] Bruhwiler, E., Kunz, P., 1993, "Remaining fatigue life of a riveted railway bridge", Proceedings of the IABSE colloquium, Copenhagen, pgs. 375-83. 
[4] Kunz, P., Hirt, M.A., 1993, "Reliability analysis of steel railway bridges under fatigue loading", Proceedings of the IABSE colloquium, Copenhagen, pgs. 53-60.

[5] Tobias, D.H., Foutch, D.A., 1995, "Reliability-based method for fatigue evaluation of railway bridges", Journal of Bridge Engineering 2(2):231-43.

[6] Fisher, J.W., Yen, B.T., Wang, D., "NCHRP Report 302: fatigue and fracture evaluation for rating riveted bridges", Technical Report, Transportation Research Board, National Research Council, Washington DC.

[7] Al-Emrani, M., 2002, "Fatigue in riveted railway bridges - a study of the fatigue performance of riveted stringers and stringer-floor-beam connections", Ph.D. Thesis, Department of Structural Engineering, Chalmers University of Technology, Goteborg, Sweden.

[8] DePiero, A.H., Paasch, R.K., Lovejoy, S.C., 2002, "Finite-element modelling of bridge deck connections details", Journal of Bridge Engineering 7(4):229-35.

[9] Al-Emrani, M., Kliger, R., 2003, "FE analysis of stringer-to-floor beam connections in riveted railway bridges", Journal of Constructional Steel Research 59(7):803-18.

[10] Iman, B. 2006, "Fatigue analysis of riveted railway bridges", Ph.D. Thesis, School of Engineering, University of Surrey, UK.

[11] Taras A, Greiner R, 2010, "Statistical Background to the Proposed Fatigue Class Catalogue for Riveted Components. Report: Contribution to WG6.1 - Assessment of Existing Steel Structures“, ECCS TC6 - 2010, Spring Meeting - Lausanne - March 22-23.

[12] Jesus, A.M.P., Pinto, H., Fernández-Canteli, A., Castillo, E., Correia, J.A.F.O., 2010, "Fatigue assessment of a riveted shear splice based on a probabilistic model", International Journal of Fatigue 32: $453-462$.

[13] Jesus, A.M.P., Silva, A.L., Correia, J.A.F.O., Fatigue of Riveted and Bolted Joints Made of Puddle Iron - A Numerical Approach, Journal of Constructional Steel Research, Submitted for publication.

[14] Castillo, E., Fernández-Canteli, A., 2009, “A Unified Statistical Methodology for Modelling Fatigue Damage”, Springer. 
[15] Paris, P.C., Erdogan, F., 1963, “A critical analysis of crack propagation laws”, Transactions of The ASME. Series E: Journal of Basic Engineering 85: 528-534.

[16] Lawrence, F.V., Jr., Mattos, R.J., Higashida, Y., Burk, J.D., 1978, "Estimation the fatigue crack initiation life of welds”, Fatigue Testing of Weldments, ASTM STP 648, D. W. Hoeppner, Eds., American Society for Testing and Materials, pgs. 134-158.

[17] Jakubczak, H., Glinka, G., 1986, "Fatigue analysis of manufacturing defects in weldments", International Journal of Fatigue 8(2): 51-57.

[18] Ribeiro, A.S., 1993, "Effect of the crack initiation phase on the Fatigue Behaviour of Welded Joints”, PhD Thesis, University of Trás-os- Montes e Alto Douro, Portugal (in Portuguese).

[19] Tricoteaux, A., Fardoun, F., Degallaix, S., Sauvage, F., 1995, "Fatigue Crack Initiation Life Prediction in High Strength Structural Steel Welded Joints”, Fatigue and Fracture of Engineering Materials and Structures 18(2): 189-200.

[20] Bhuyan, G., Vosikovsky, O., 1989, "Prediction of fatigue crack initiation lives for welded plate Tjoints based on the local stress-strain approach", International Journal of Fatigue 11(3): 153-159.

[21] Cheng, G., Kuang, Z.B., Lou, Z.W., Li, H., 1996, “Experimental investigation of fatigue behavior for welded joint with mechanical heterogeneity", International Journal of Pressure Vessel \& Piping 67: 229-242.

[22] Radaj, D., Sonsino, C.M., 1998, "Fatigue Assessment of Welded Joints By Local Approaches", Abington Publishing, Cambridge, England.

[23] Krueger, R., 2004, "Virtual crack closure technique: History, approach, and applications", Applied Mechanics Reviews 57(2): 109-143.

[24] Neuber, H., 1961, “Theory of Stress Concentration for Shear-Strained Prismatic Bodies with Arbitrary Nonlinear Stress-Strain Law”, Journal of Applied Mechanics 28: 544-550.

[25] Seeger, T., Heuler, P., 1980, “Generalised application of Neuber's rule”, Journal Testing Evaluation 8(4): 199-204. 
[26] Kalnins A., 2006, "Fatigue Analysis in Pressure Vessel Design by Local Strain Approach: Methods and Software Requirements", Journal of Pressure Vessel Technology 128: 2-7.

[27] Silva, A., 2009, "Fatigue behaviour of a material from a centenary metallic bridge under the action of complex loading”, MScThesis, University of Trás-os- Montes e Alto Douro, Portugal (in Portuguese).

[28] ASTM E606-92: Standard Practice for Strain Controlled Fatigue Testing. Annual Book of ASTM Standards, Vol. 03.01, West Conshohocken, PA, 557-571.

[29] Morrow, J. D., 1965, “Cyclic plastic strain energy and fatigue of metals”, Int. Friction, Damping and Cyclic Plasticity, ASTM, STP 378, pgs. 45-87.

[30] Ramberg, W., Osgood, W.R., 1943, "Description of stress-strain curves by three parameters”, Naca TN 402, National Advisory Committee for Aeronautics.

[31] ASTM E647: Standard Test Method for Measurement of Fatigue Crack Growth Rates. Annual Book of ASTM Standards, Vol. 03.01, West Conshohocken, PA, 591-630.

[32] ANSYS. Swanson Analysis Systems Inc. Houston, Version 12.1; 2009.

[33] Besseling, J.F., 1958, “A theory of elastic, plastic, and creep deformations of an initially isotropic material showing anisotropic strain-hardening creep recovery and secondary creep", Journal of Applied Mechanics, 529-36. 


\section{List of Tables}

Table 1 - Summary of the parametric study

$\underline{\text { Table } 2 \text { - Goodness of fit statistical tests, for several probabilistic density functions. }}$ 


\section{List of Figures Captions}

Figure 1 - Procedure for probabilistic fatigue life assessment of riveted joints.

$\underline{\text { Figure } 2 \text { - Double shear riveted joint: a) technical representation (dimensions in } \mathrm{mm} \text { ); b) }}$ photograph of some riveted joints.

Figure 3 - Experimental S-N data of the riveted joint.

Figure 4 -Strain-life data of the puddle iron from the Fão bridge.

Figure 5 - Strain-life data: cumulative distributions of the number of reversals to failure for distinct strain amplitudes.

Figure 6 - Fatigue crack propagation data of the puddle iron.

Figure 7 - Cumulative probability distribution of coefficient $C$.

Figure 8 - Experimental and simulated fatigue crack propagation data: $C$ fixed (4.20E18) and $m$ random accordingly LogNormal distribution with average value of 4.80 and

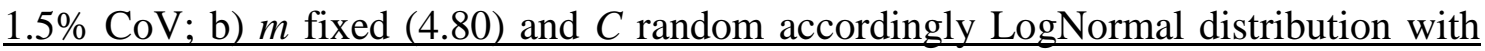
average value of $4.20 \mathrm{E}-18$ and $50 \% \mathrm{CoV}$.

Figure 9 - Finite element mesh of the $1 / 8$ of the riveted joint.

Figure 10 - Evolution of the average thru-thickness mode I stress intensity factor with the crack size, clamping stress on rivets and friction coefficient.

Figure 11 -Comparison of component cyclic stress-strain curves obtained using distinct approaches ( $\mu=0.15$, null clamping stress on rivets).

Figure 12 - Component elastoplastic cyclic curves.

Figure 13 - Input distributions for reference simulation (simulation 1).

Figure 14 - Output distributions for reference simulation carried out with $\underline{\Delta \sigma_{\text {net }}}=\underline{291 \mathrm{MPa}}$.

Figure 15 - Probabilistic cyclic stress-strain curves of the component.

Figure $16-p-s-N_{i}$ field resulted from reference simulation.

Figure $17-p-s-N_{p}$ field resulted from reference simulation. 
Figure $18-p-s-N_{f}$ field resulted from reference simulation.

Figure 19 - Comparison of $p-s-N_{f}$ fields from reference simulation and simulations 2,3 , $\underline{4 \text { and } 5 .}$.

Figure 20 - Comparison of $p-s-N_{f}$ fields from reference simulation and simulations 10 and 11.

Figure 21 - Comparison of $p-s-N_{f}$ fields from reference simulation and simulations 15 and 16.

Figure 22 - Fitting of simulated probabilistic density functions for the local strain amplitude and the number of cycles to failure (Simulation $1, \Delta \sigma_{n e t}=355 \mathrm{MPa}$ ).

Figure 23 - Comparison of $p-s-N_{f}$ fields from reference simulation and AREMA S-N curve as well as Taras \& Greiner S-N curve proposal. 


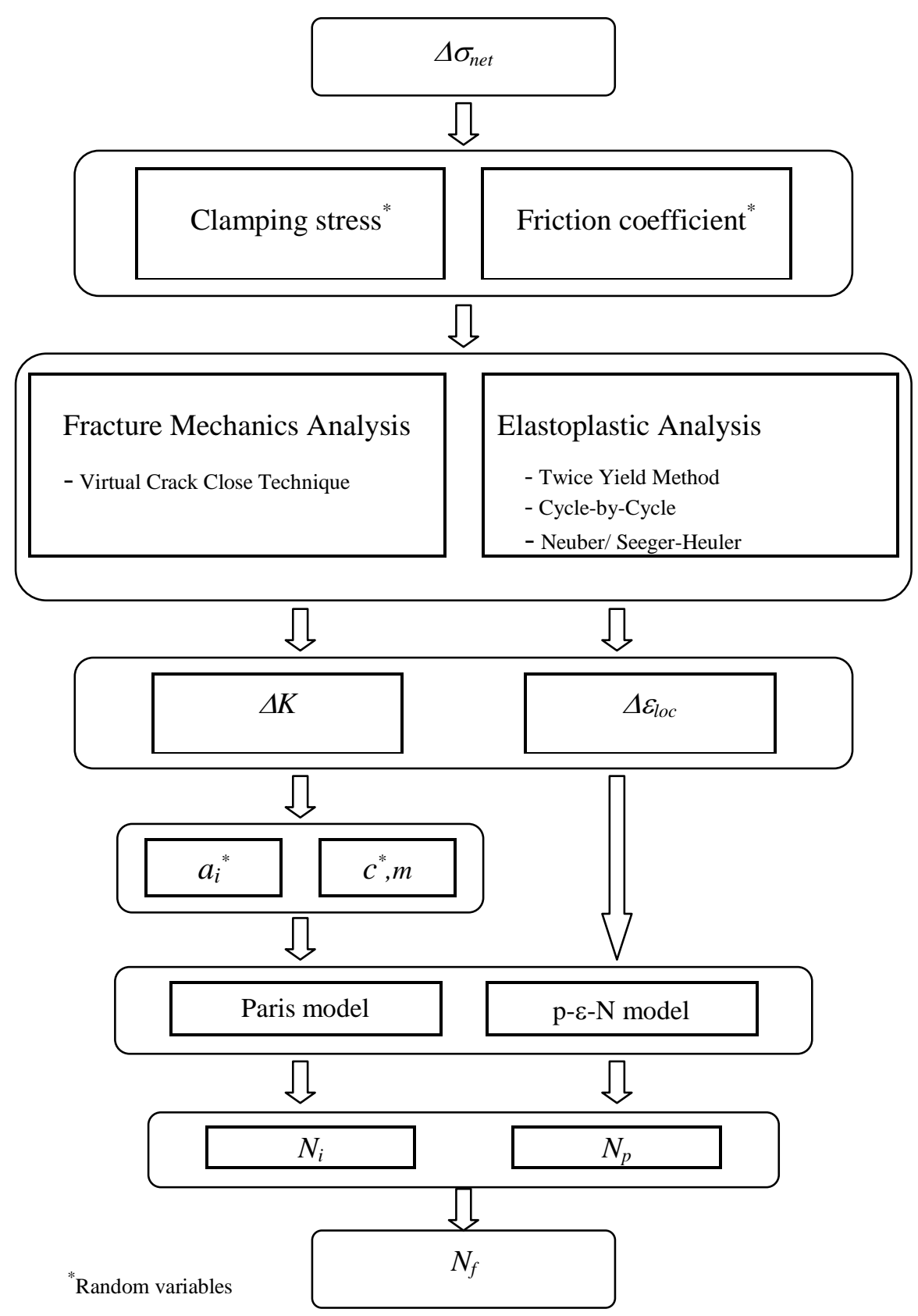

Figure 1 - Procedure for probabilistic fatigue life assessment of riveted joints. 

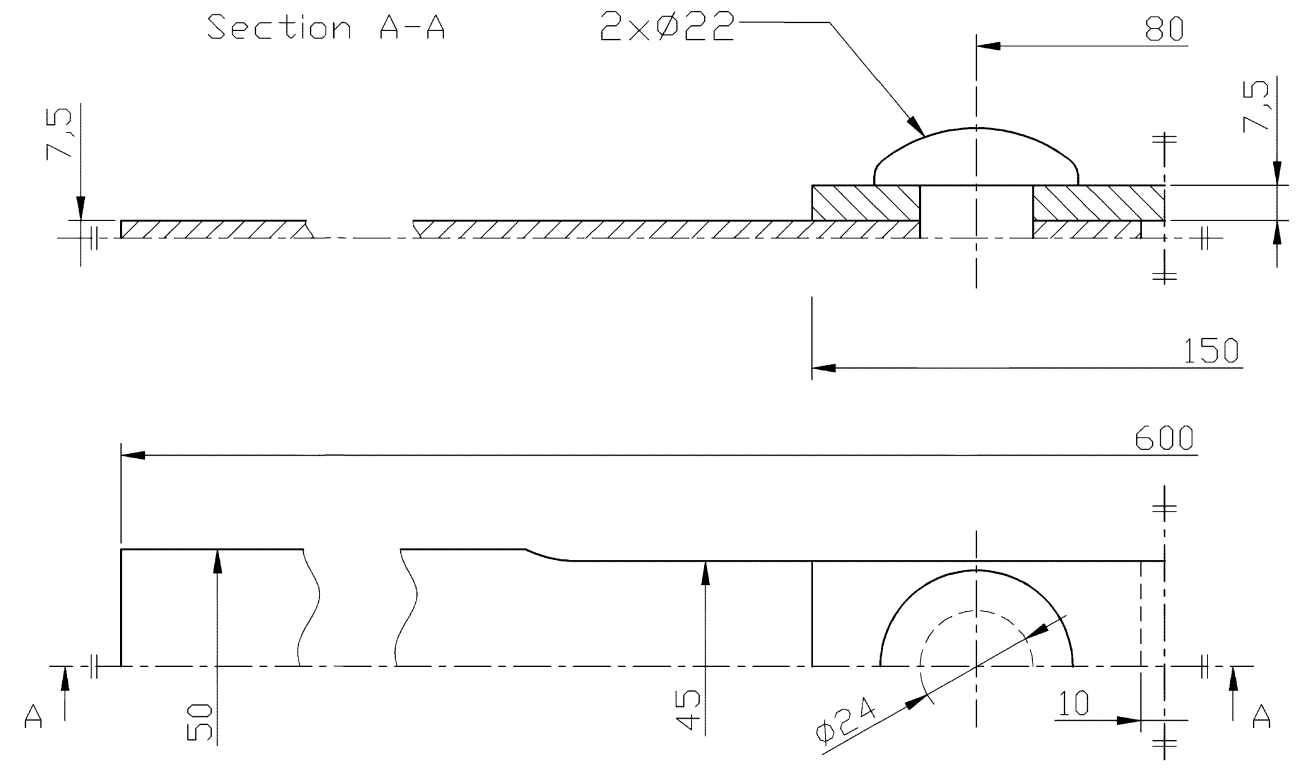

a)

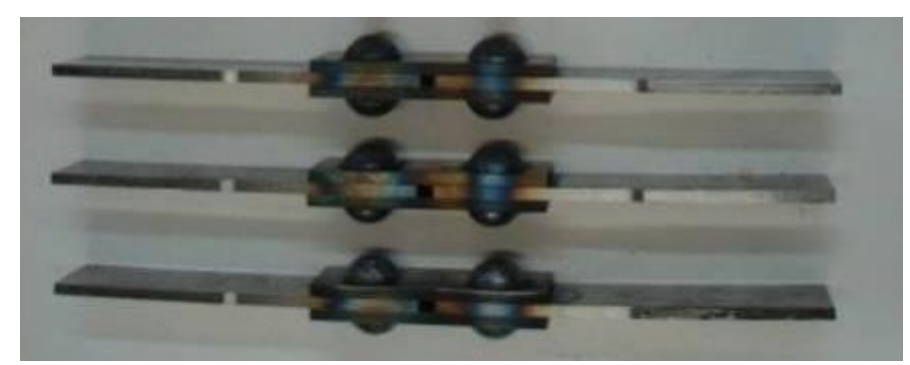

b)

Figure 2 - Double shear riveted joint: a) technical representation (dimensions in $\mathrm{mm}$ ); b) photograph of some riveted joints. 


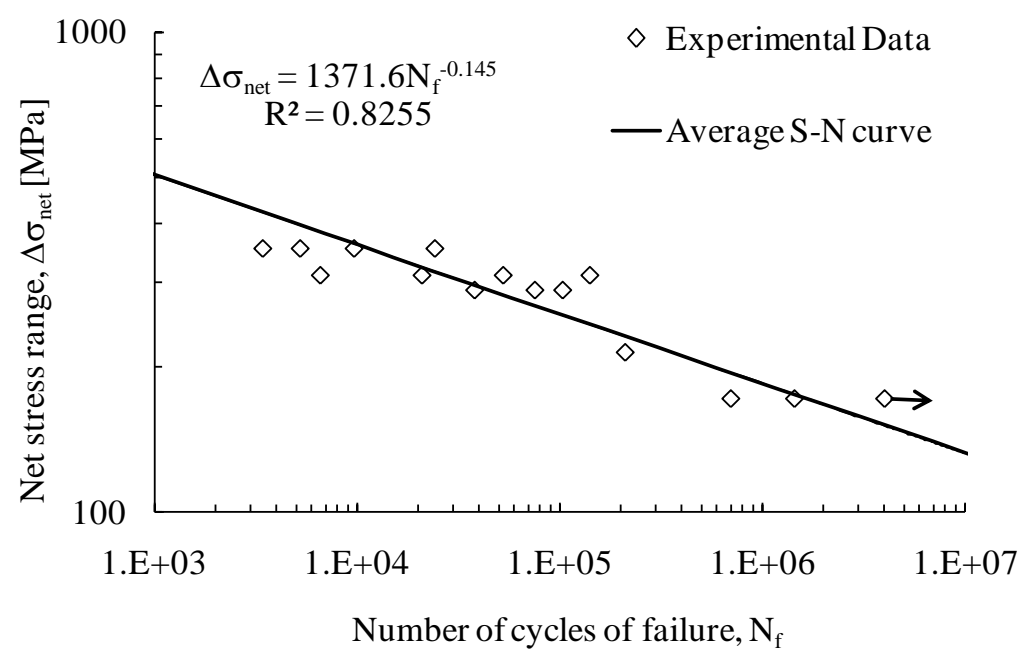

Figure 3 - Experimental S-N data of the riveted joint. 


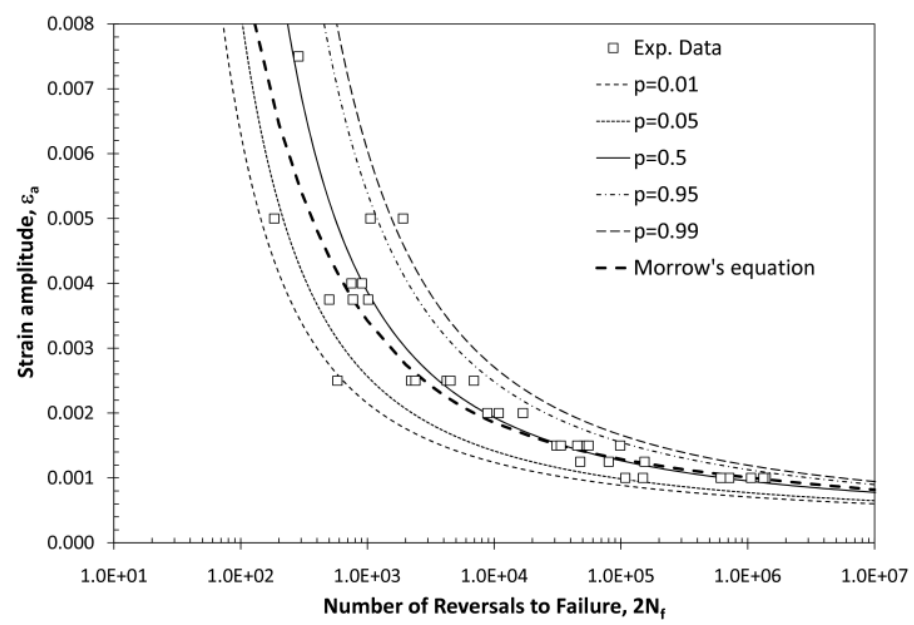

Figure 4 -Strain-life data of the puddle iron from the Fão bridge. 


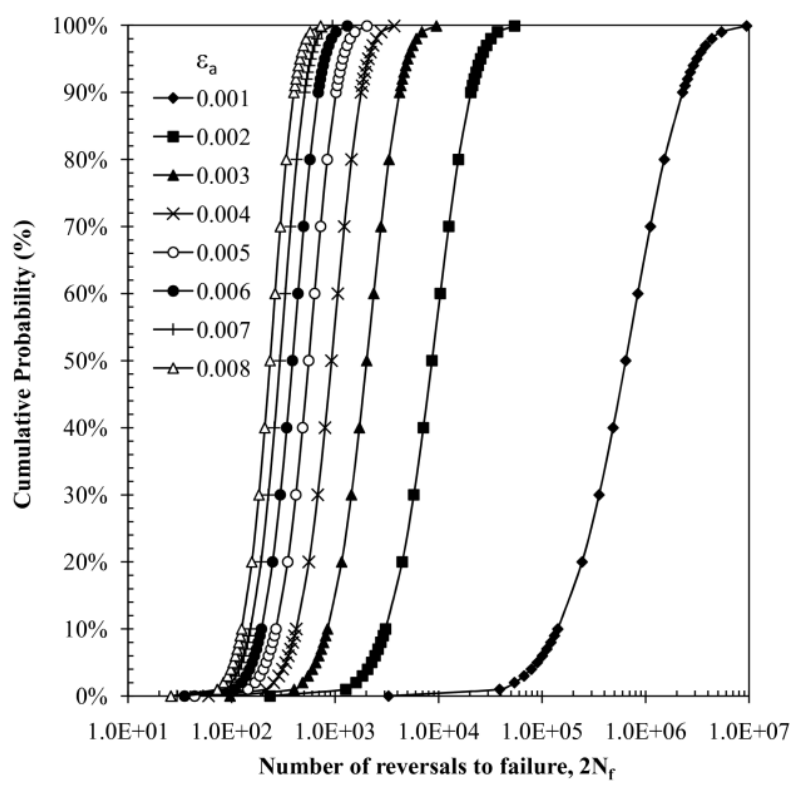

Figure 5 - Strain-life data: cumulative distributions of the number of reversals to failure for distinct strain amplitudes. 


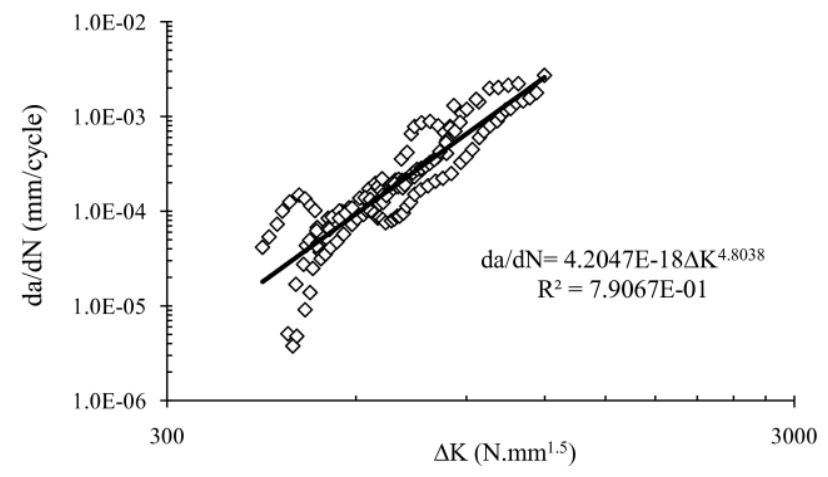

Figure 6 - Fatigue crack propagation data of the puddle iron. 


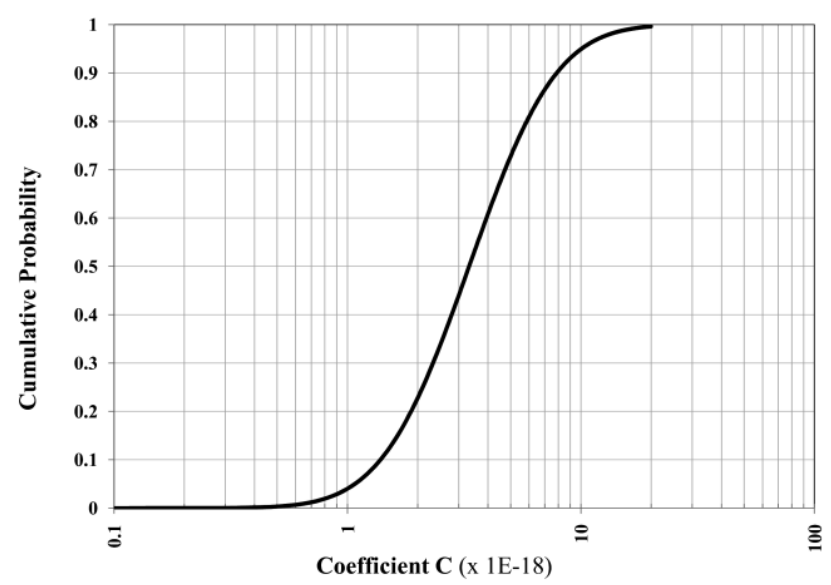

Figure 7 - Cumulative probability distribution of coefficient $C$. 

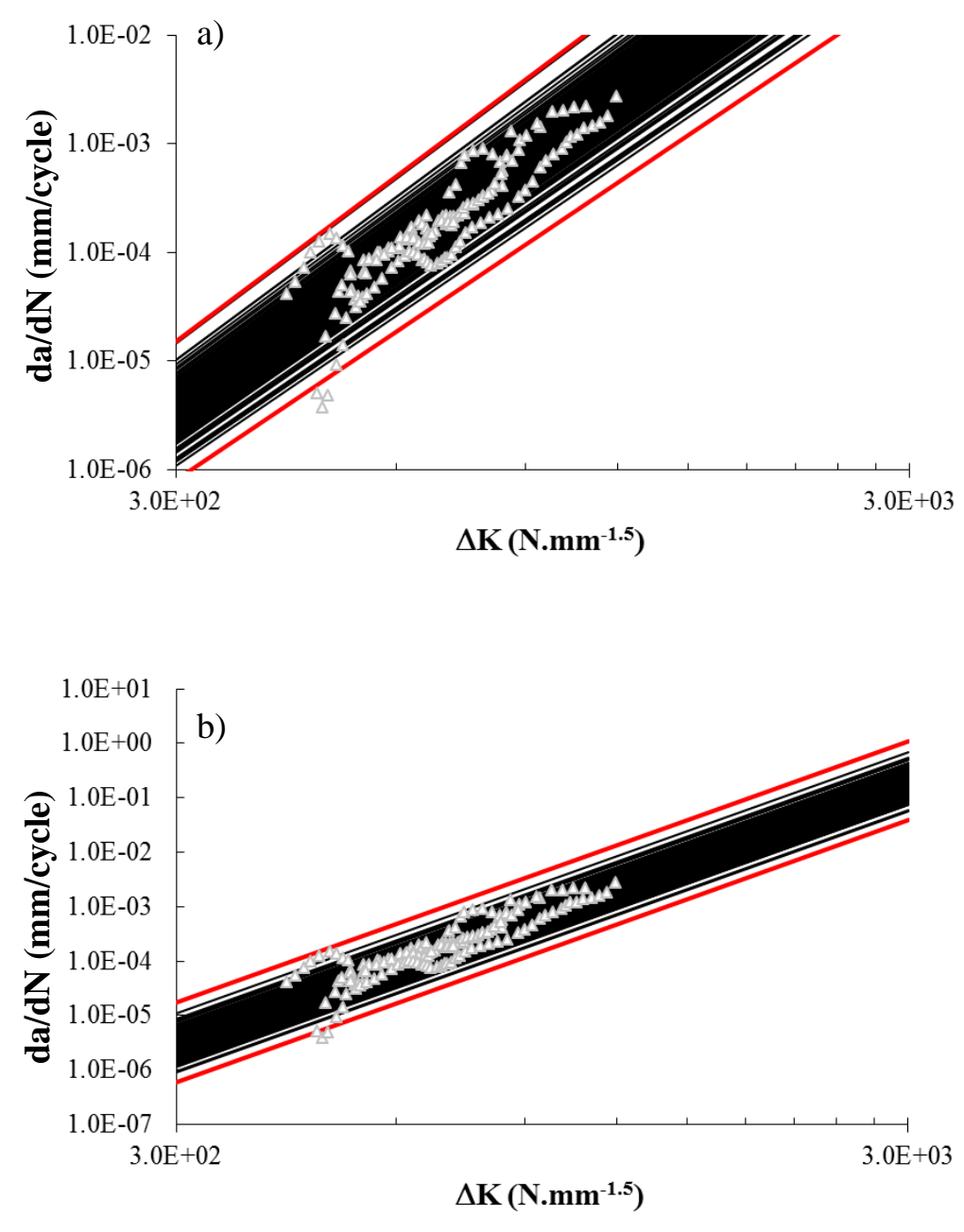

Figure 8 - Experimental and simulated fatigue crack propagation data: $C$ fixed (4.20E18 ) and $m$ random accordingly LogNormal distribution with average value of 4.80 and $1.5 \% \mathrm{CoV}$; b) $m$ fixed (4.80) and $C$ random accordingly LogNormal distribution with average value of $4.20 \mathrm{E}-18$ and $50 \% \mathrm{CoV}$. 


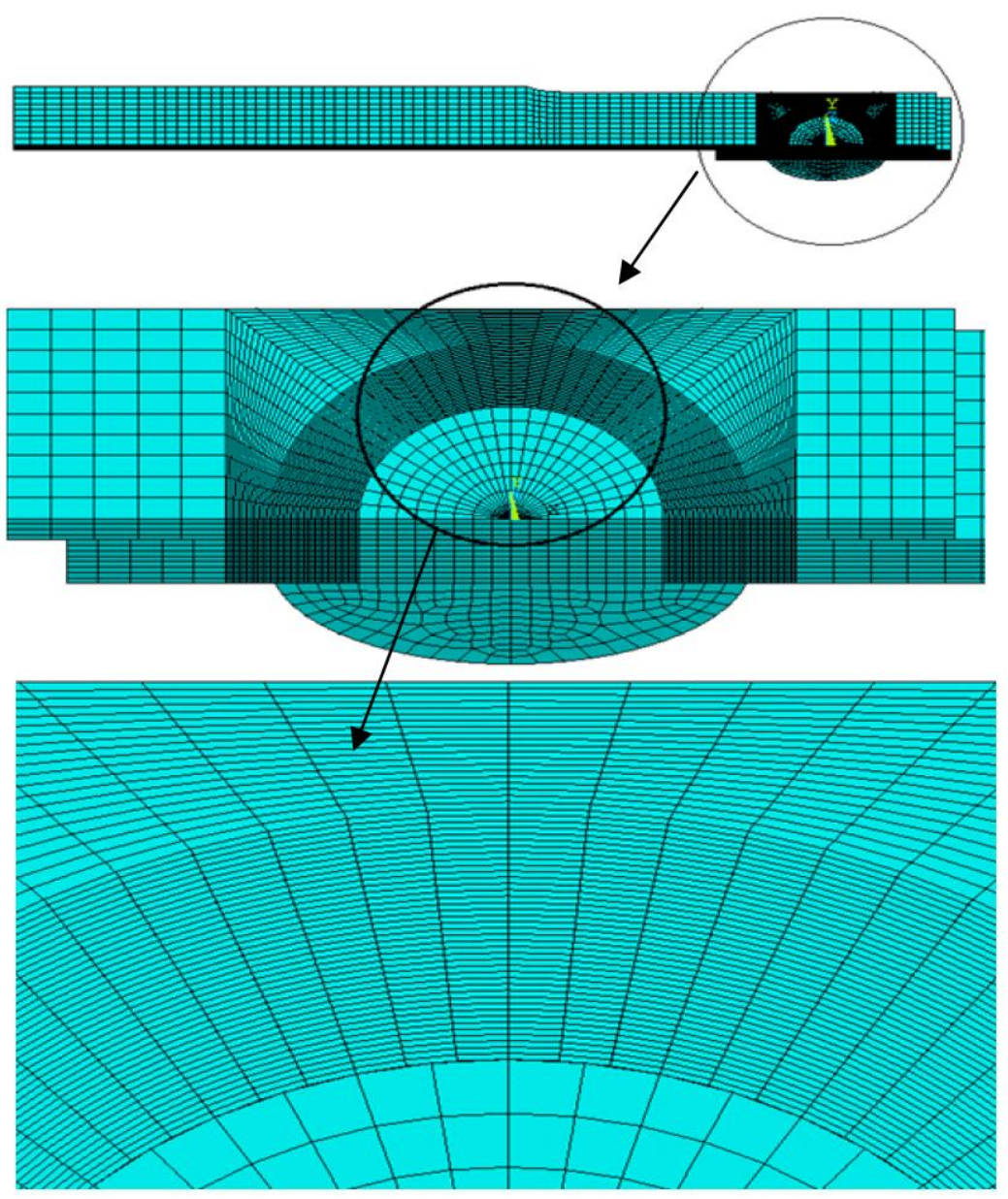

Figure 9 - Finite element mesh of the $1 / 8$ of the riveted joint. 

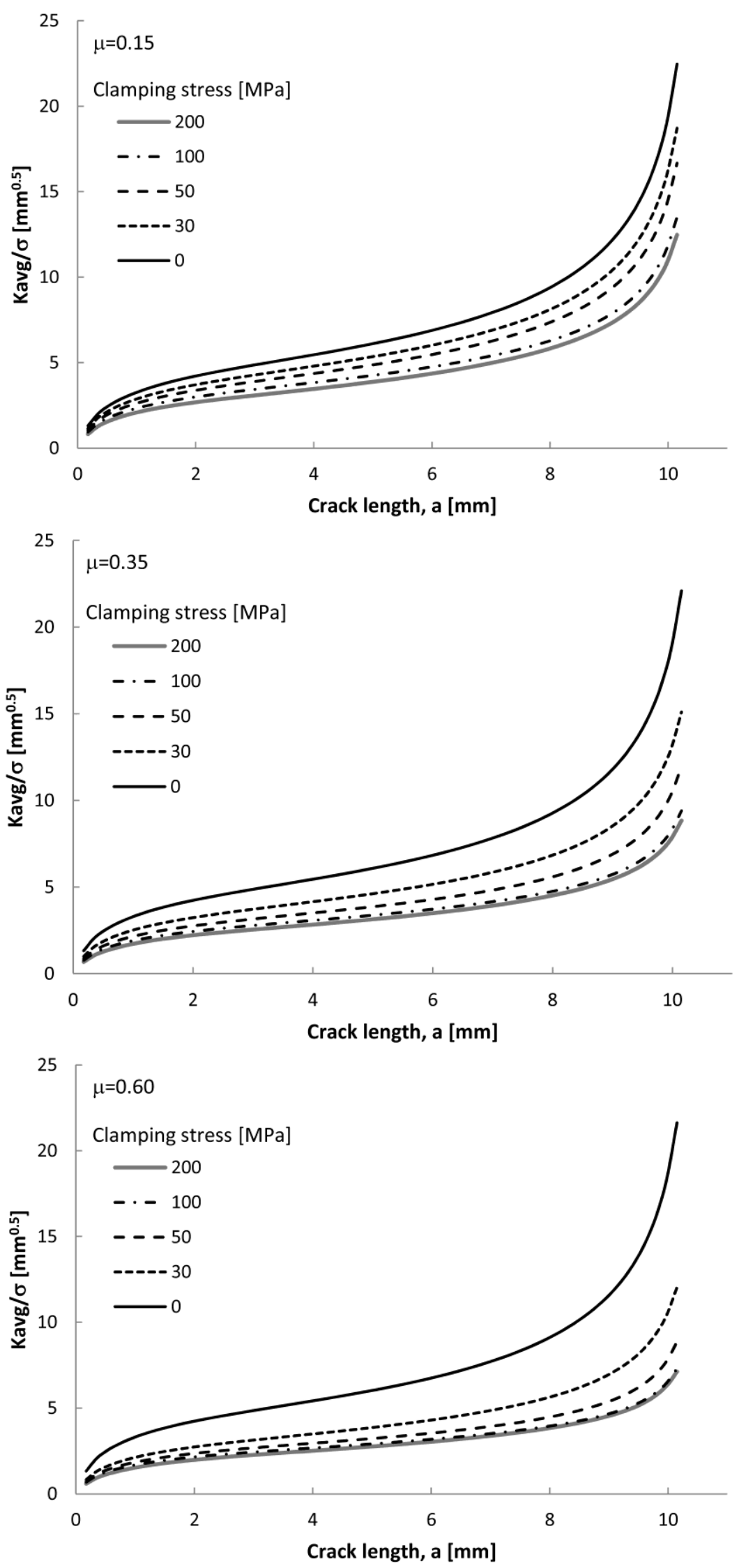

Figure 10 - Evolution of the average thru-thickness mode I stress intensity factor with the crack size, clamping stress on rivets and friction coefficient. 


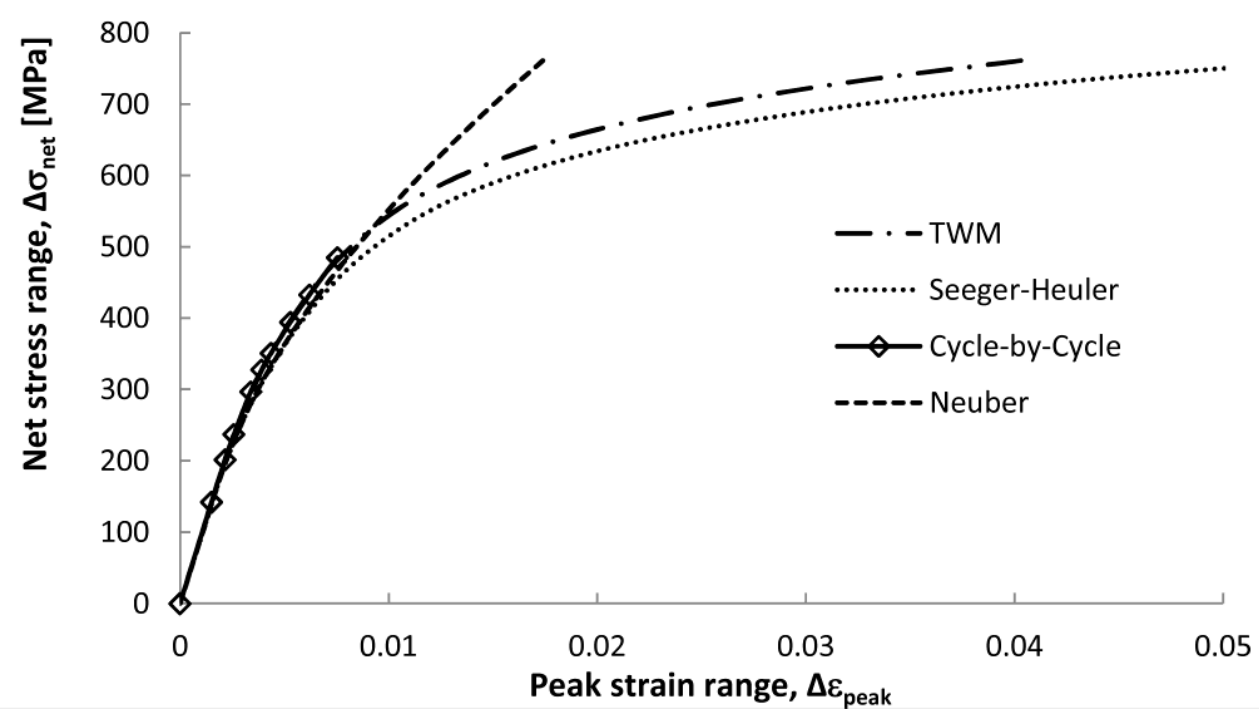

Figure 11 - Comparison of component cyclic stress-strain curves obtained using distinct approaches $(\mu=0.15$, null clamping stress on rivets). 

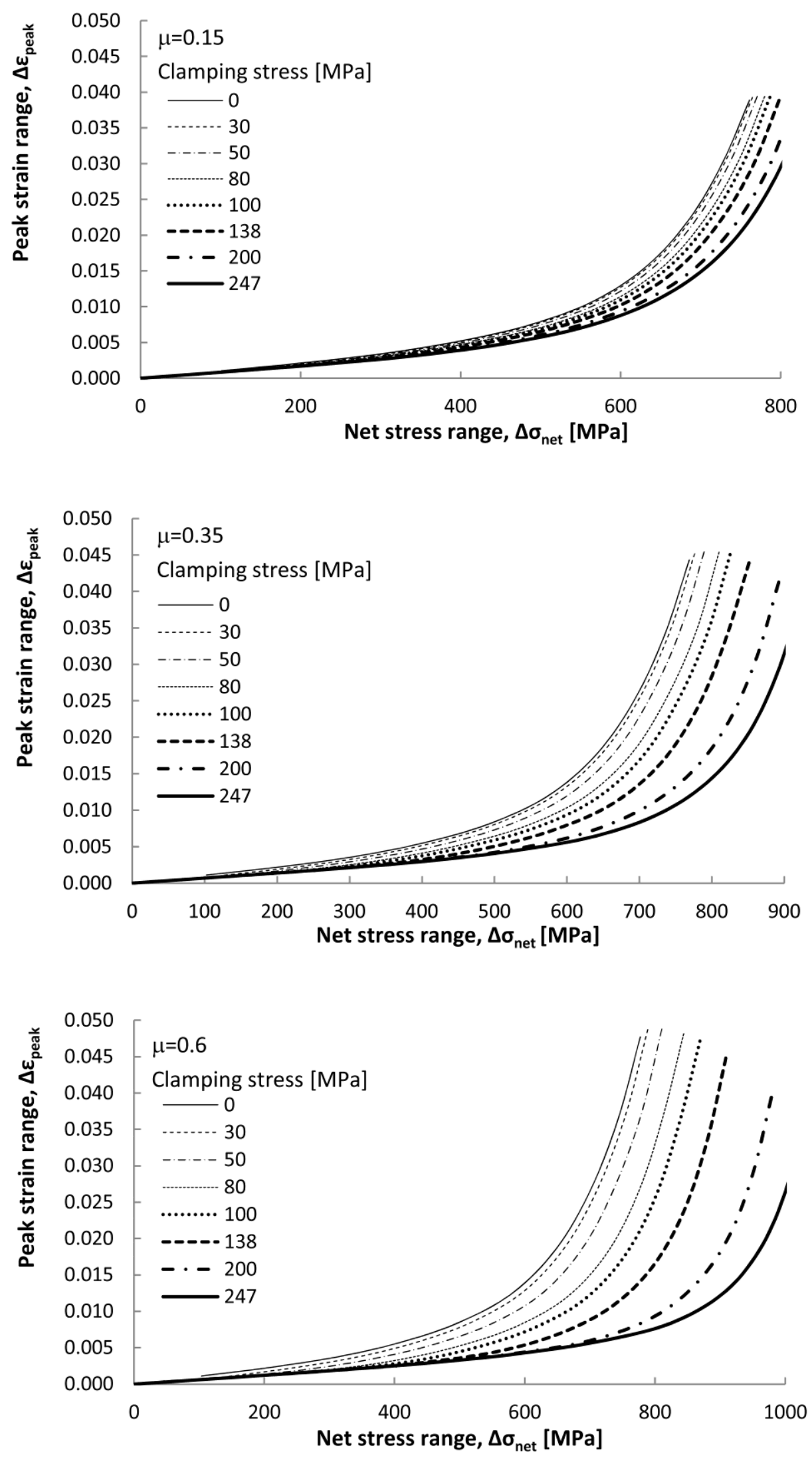

Figure 12 - Component elastoplastic cyclic curves. 

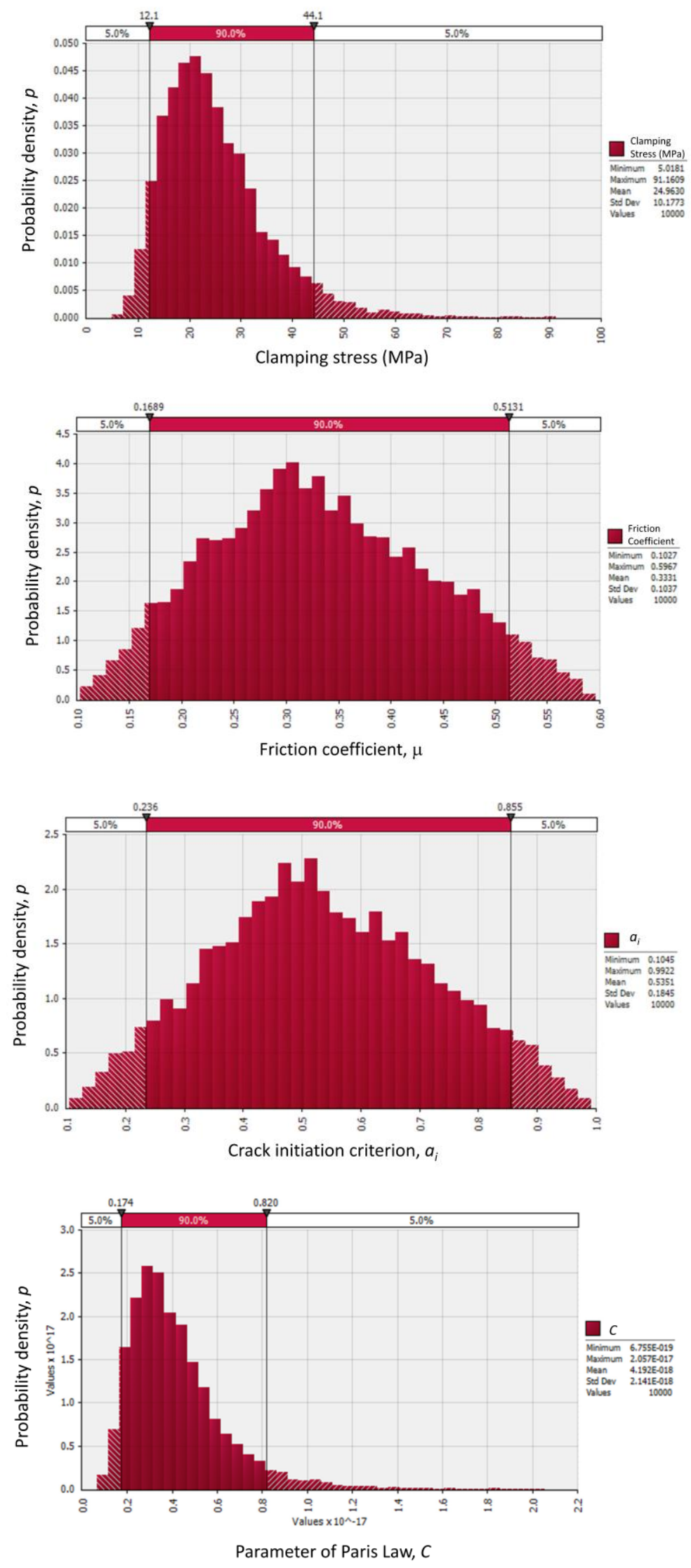

Figure 13 - Input distributions for reference simulation (simulation 1). 

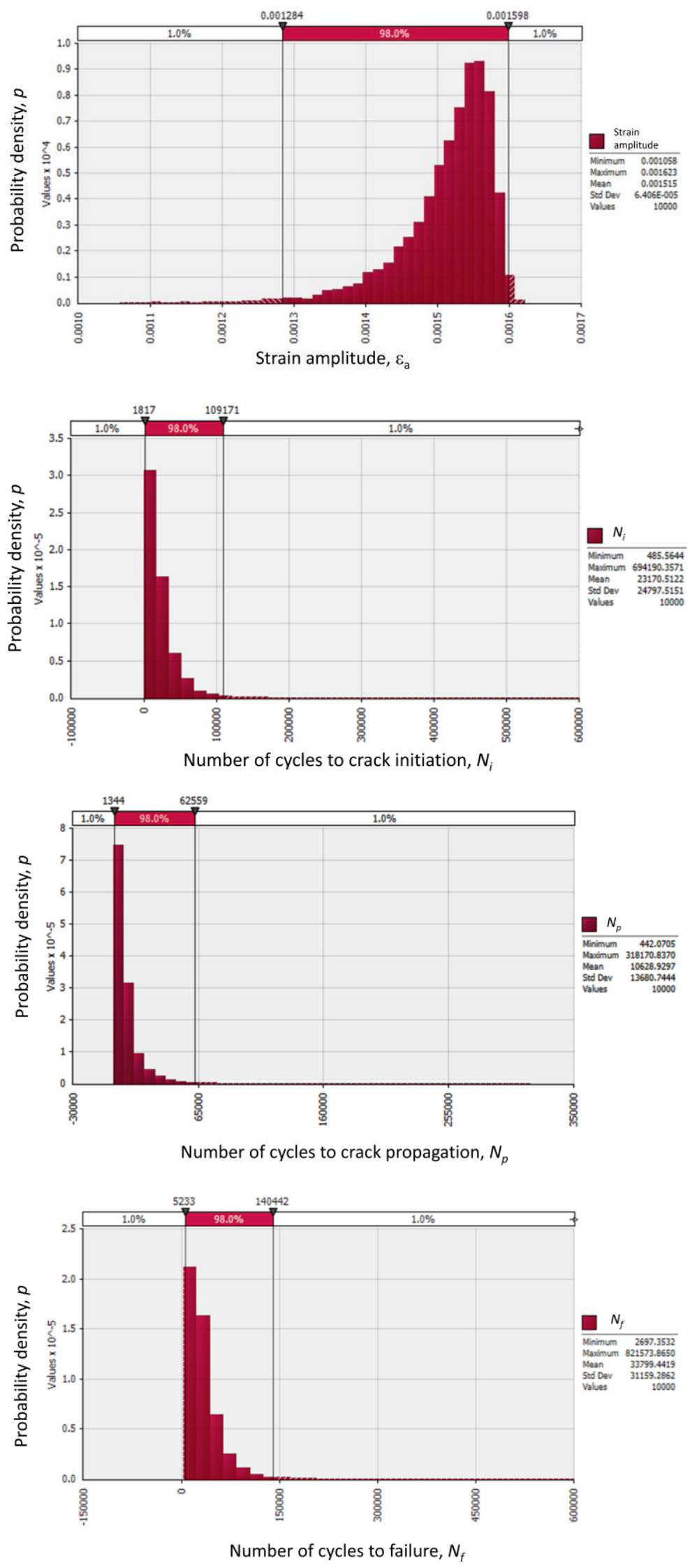

Figure 14 - Output distributions for reference simulation carried out with $\Delta \sigma_{n e t}=291 \mathrm{MPa}$. 


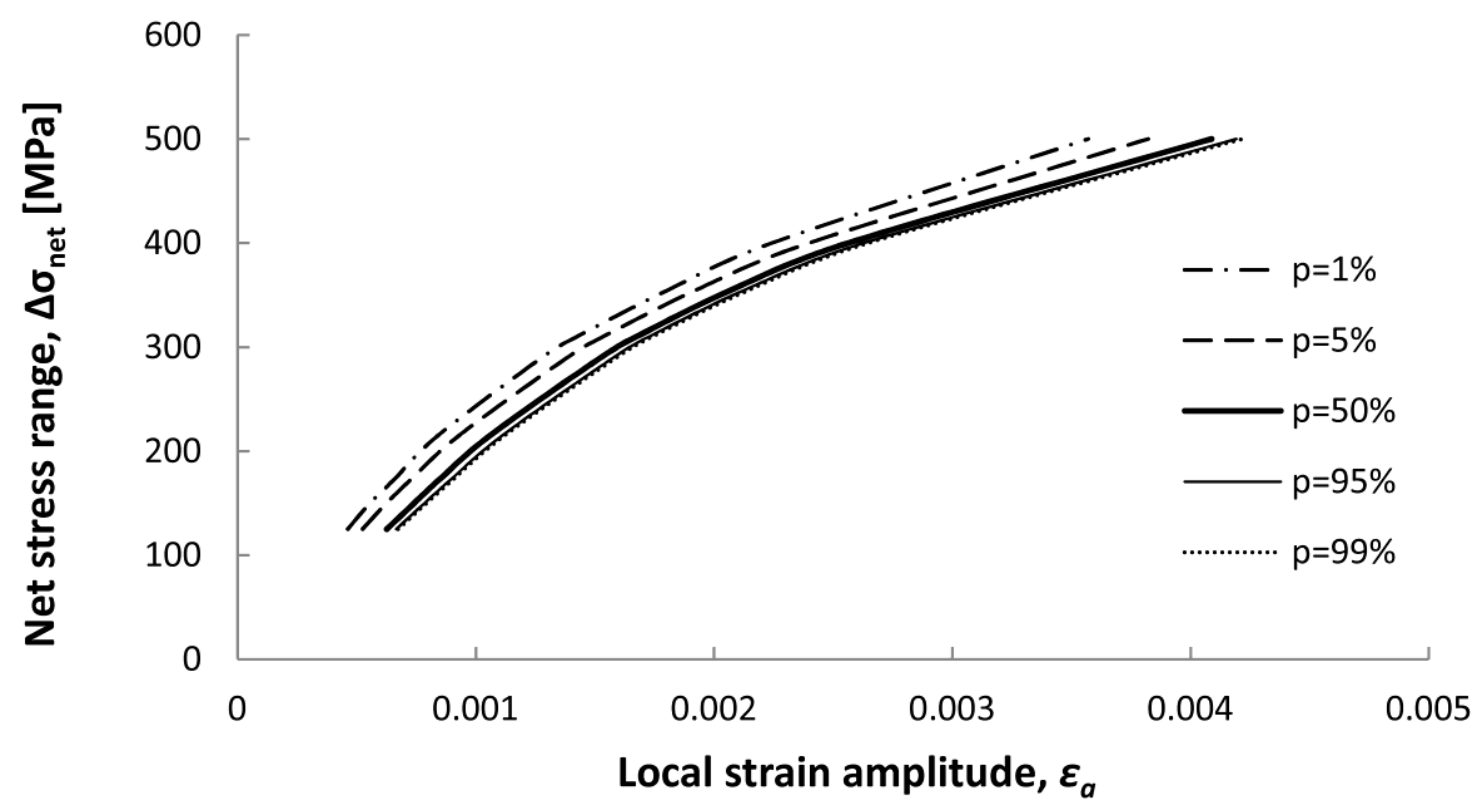

Figure 15 - Probabilistic cyclic stress-strain curves of the component. 


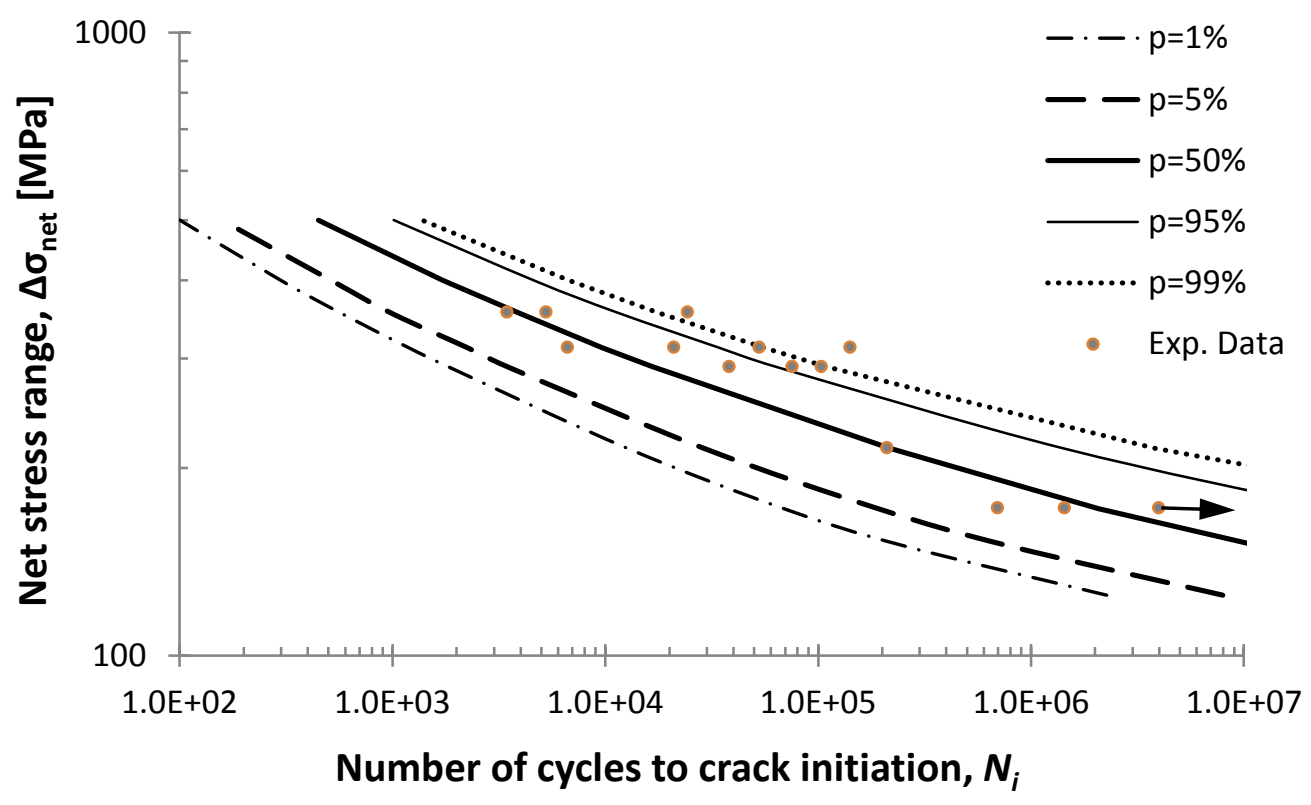

Figure $16-p-s-N_{i}$ field resulted from reference simulation. 


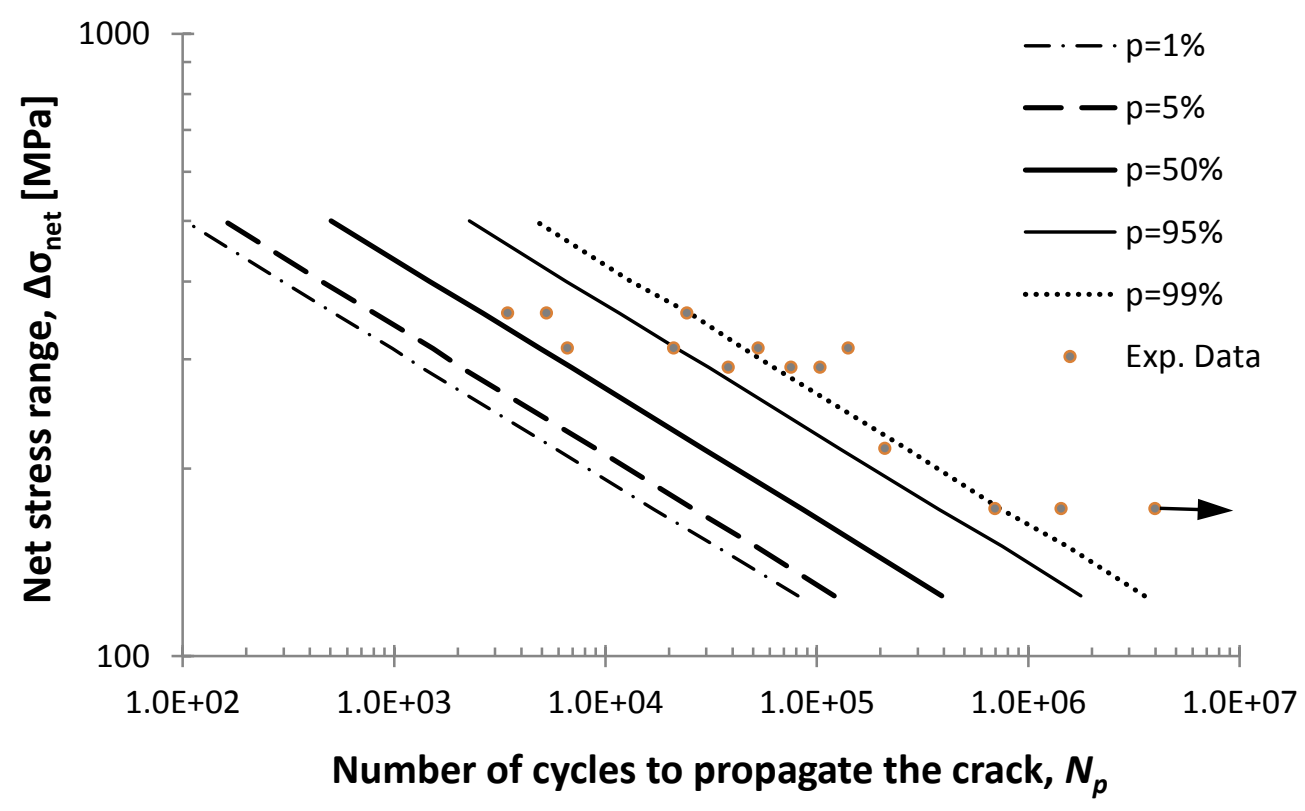

Figure $17-p-s-N_{p}$ field resulted from reference simulation. 


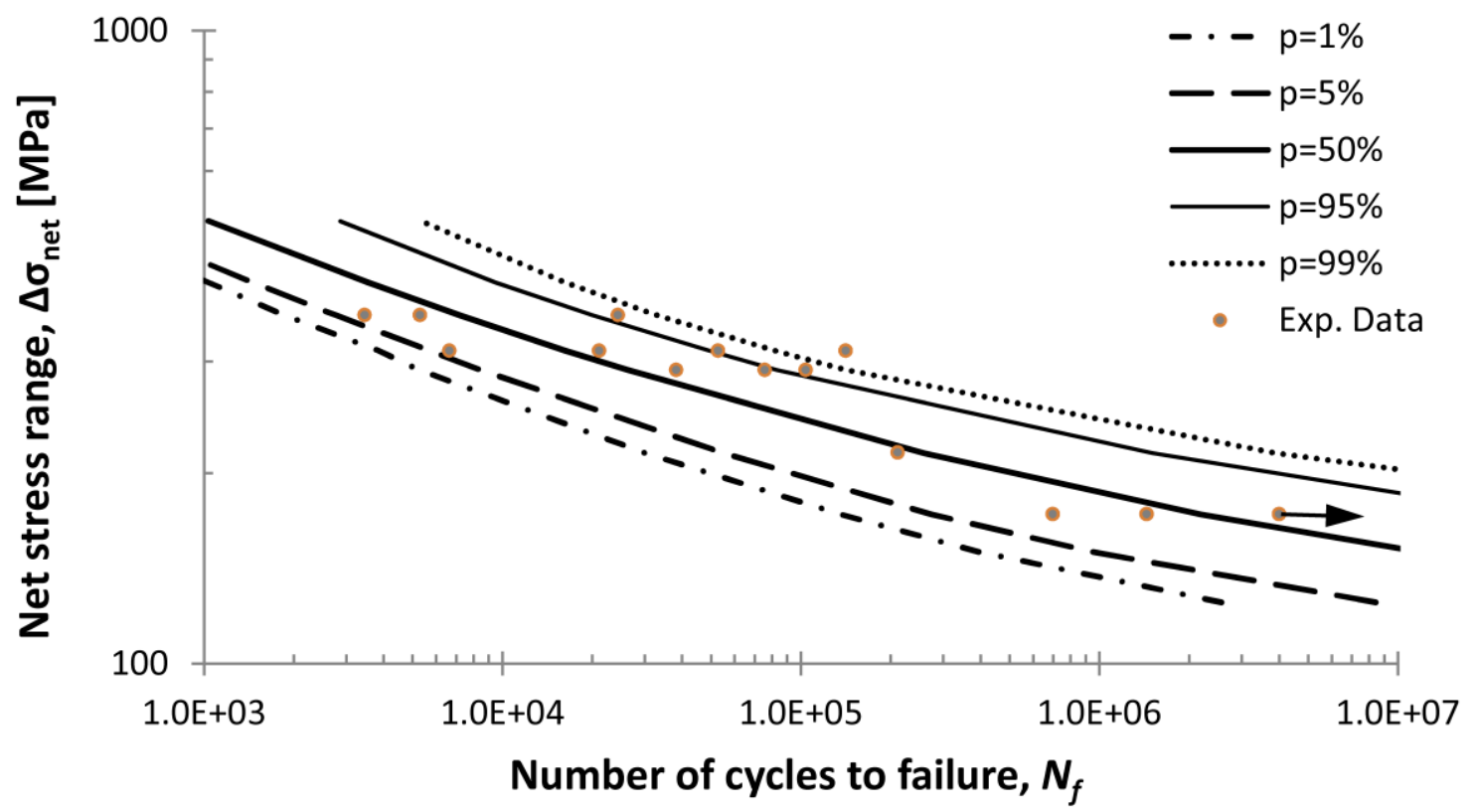

Figure $18-p-s-N_{f}$ field resulted from reference simulation. 

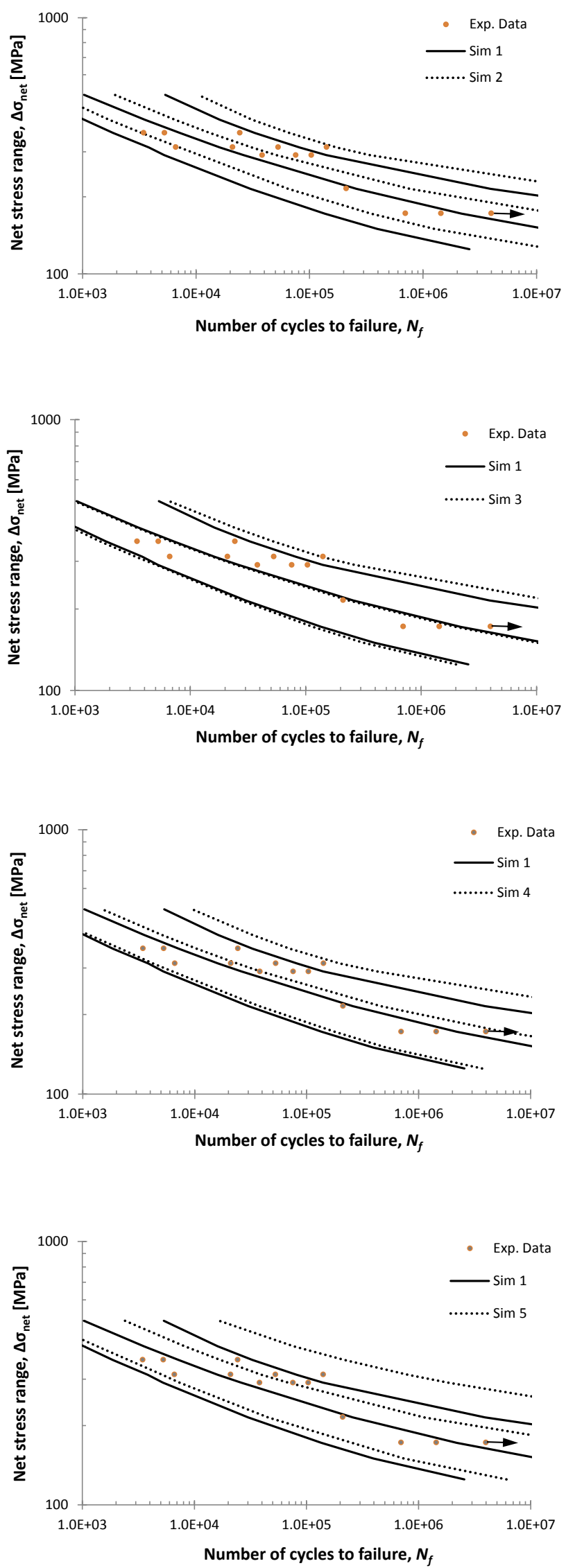

Figure 19 - Comparison of $p$-s- $N_{f}$ fields from reference simulation and simulations 2,3 , 4 and 5. 

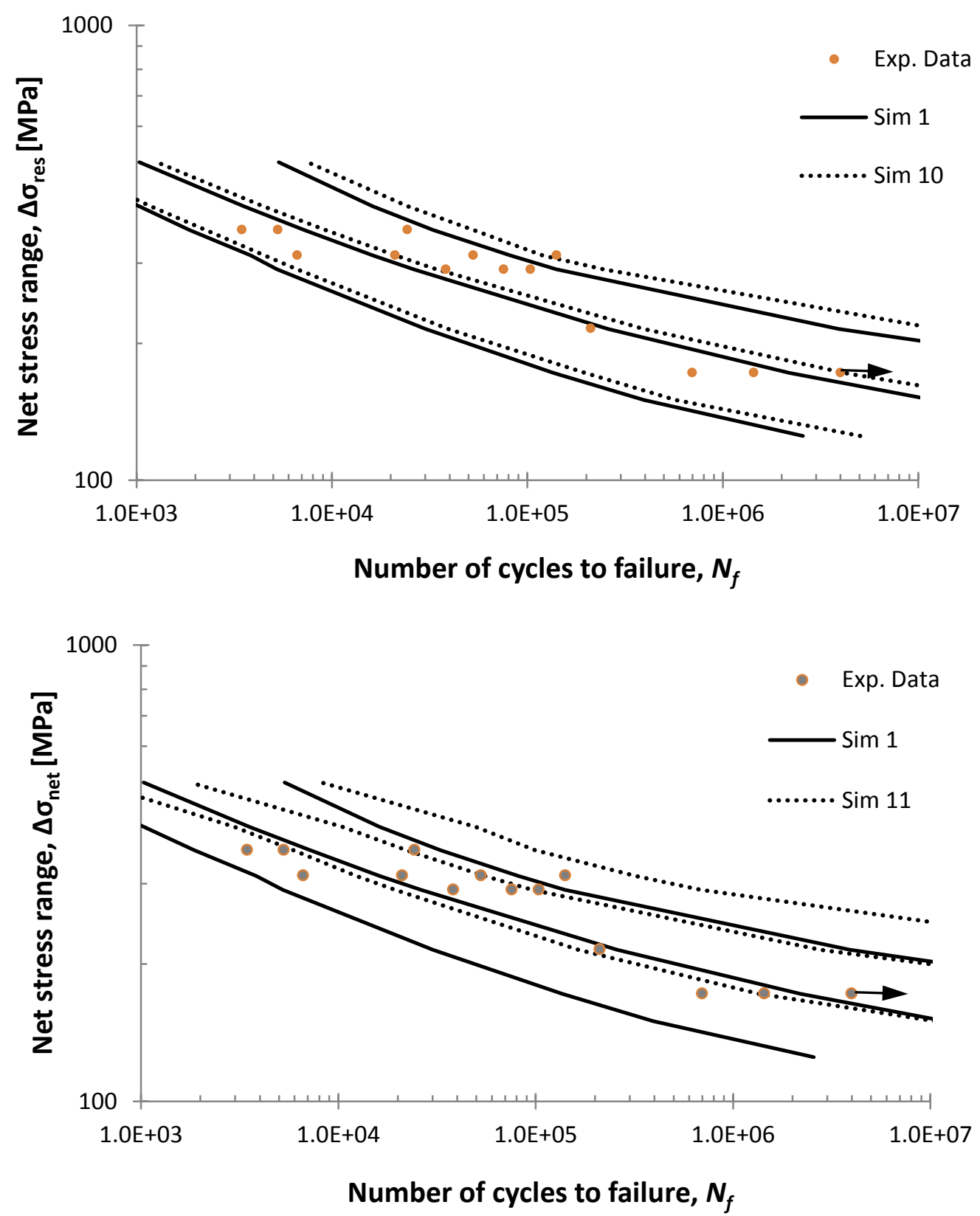

Figure 20 - Comparison of $p-s-N_{f}$ fields from reference simulation and simulations 10 and 11. 

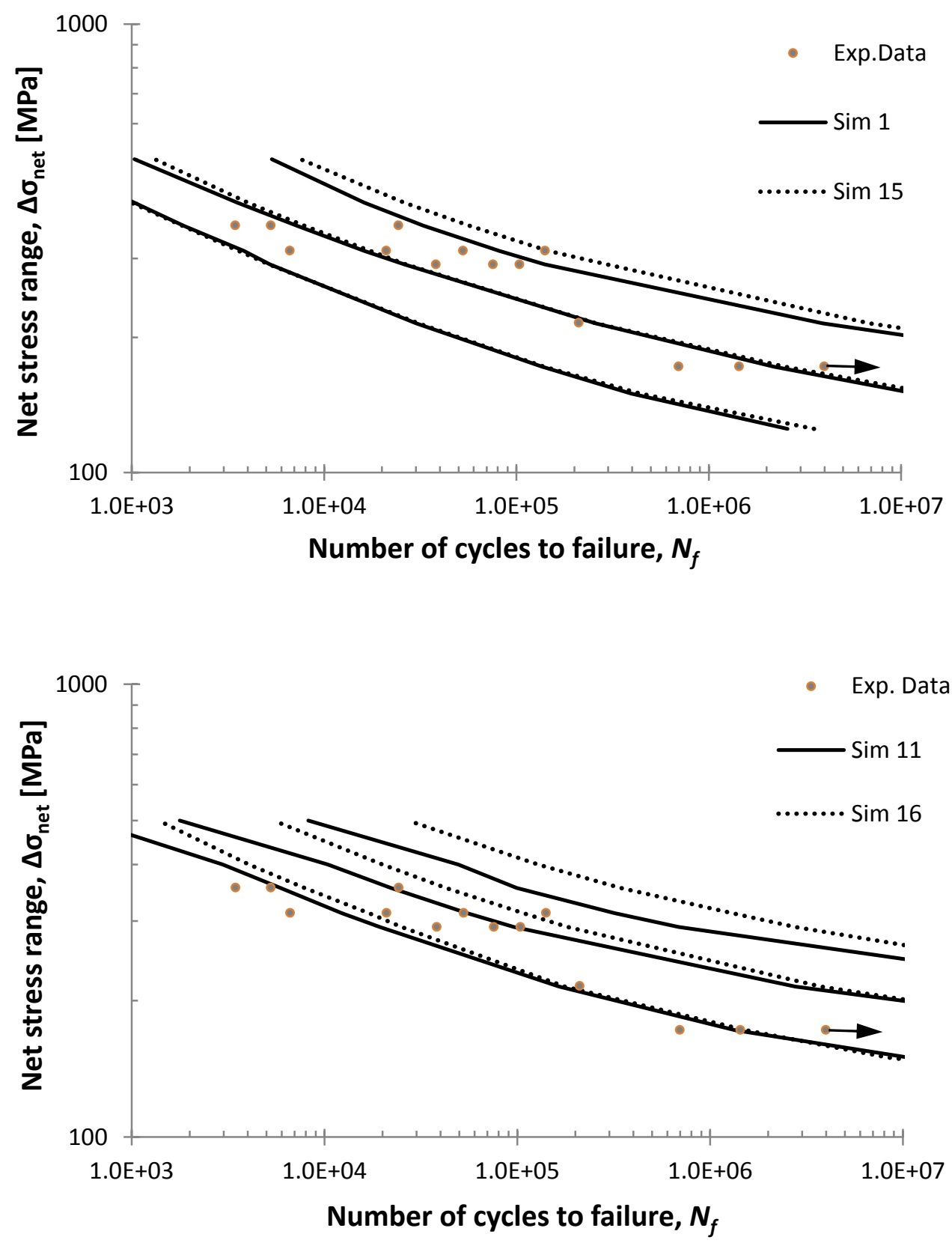

Figure 21 - Comparison of $p-s-N_{f}$ fields from reference simulation and simulations 15 and 16. 

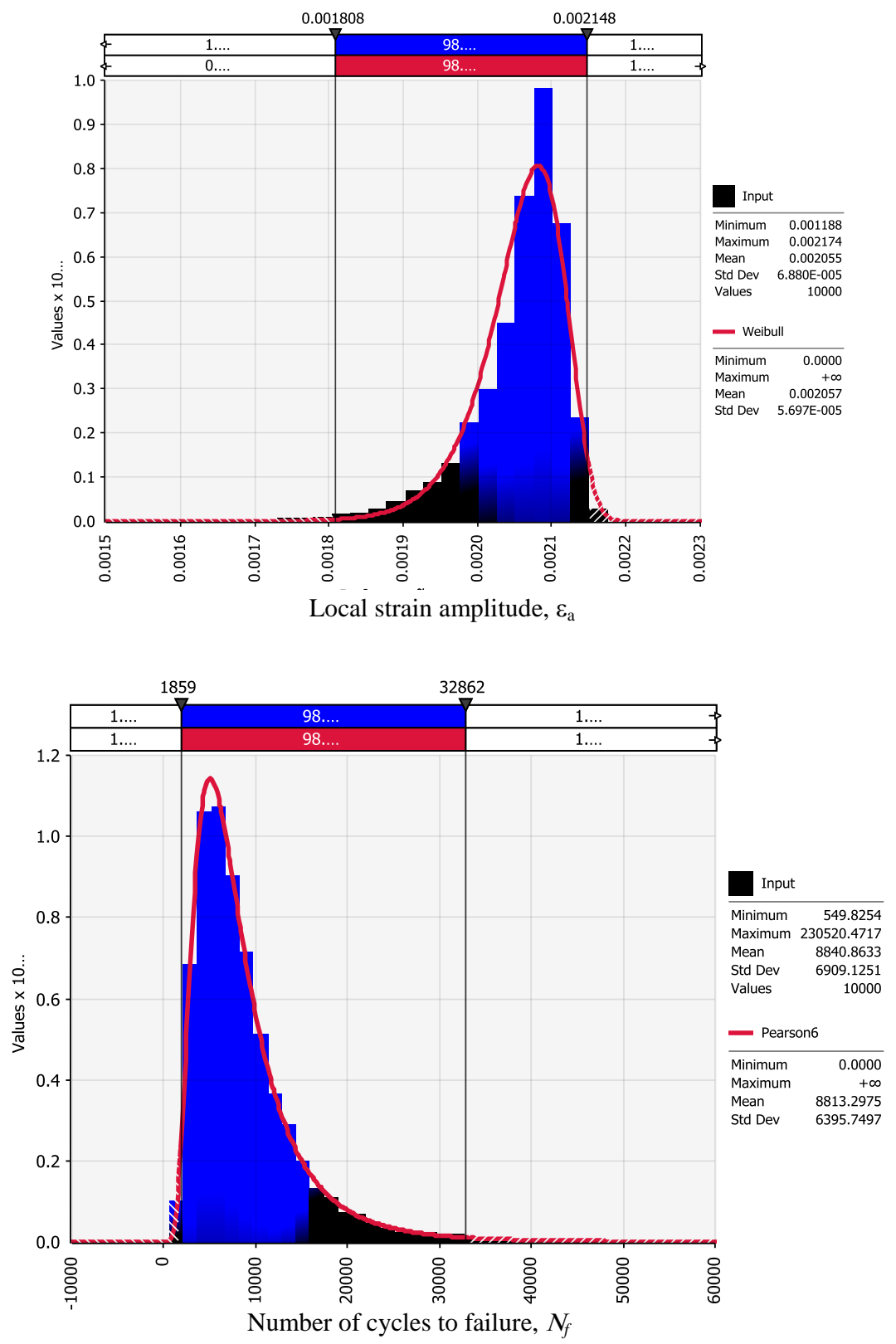

Figure 22 - Fitting of simulated probabilistic density functions for the local strain amplitude and the number of cycles to failure (Simulation $1, \Delta \sigma_{n e t}=355 \mathrm{MPa}$ ). 


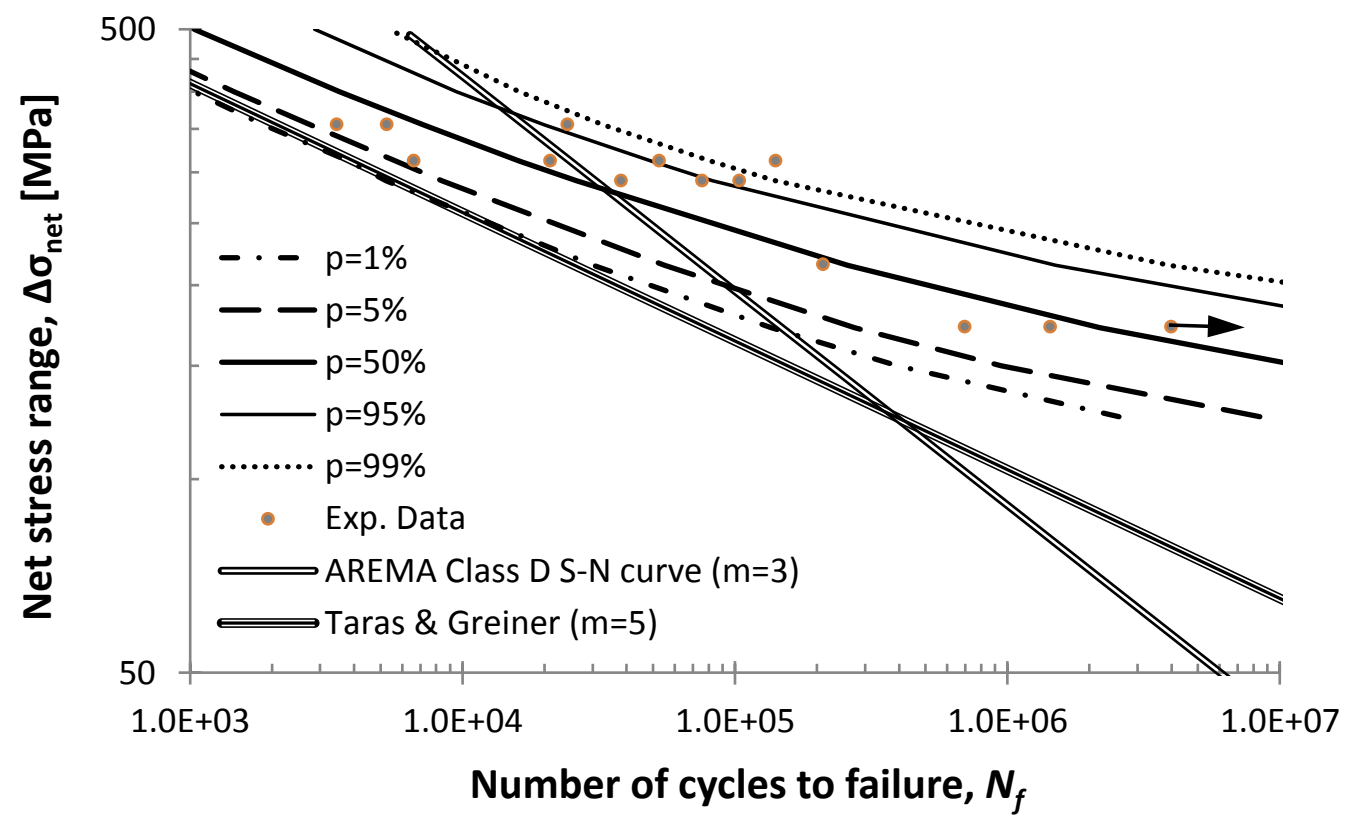

Figure 23 - Comparison of $p-s-N_{f}$ fields from reference simulation and AREMA S-N curve as well as Taras \& Greiner S-N curve proposal. 